University of Wollongong

Research Online

Faculty of Engineering and Information

Faculty of Engineering and Information

Sciences - Papers: Part B

Sciences

2018

\title{
Mechanical behaviour of micro-fine steel fibre reinforced sulphoaluminate cement composite
}

Hu Feng

Zhengzhou University, hfeng@uow.edu.au

Gang Chen

Henan University of Engineering, University of Wollongong

Muhammad N. S Hadi

University of Wollongong, mhadi@uow.edu.au

M Neaz Sheikh

University of Wollongong, msheikh@uow.edu.au

Bowen Zhou

Tongji University

Follow this and additional works at: https://ro.uow.edu.au/eispapers1

Part of the Engineering Commons, and the Science and Technology Studies Commons

Research Online is the open access institutional repository for the University of Wollongong. For further information contact the UOW Library: research-pubs@uow.edu.au 


\title{
Mechanical behaviour of micro-fine steel fibre reinforced sulphoaluminate cement composite
}

\author{
Abstract \\ In this study, a new cement-based composite with high early strength and toughness was developed by \\ the addition of micro-fine steel fibre (MSF) in sulphoaluminate cement (SAC). The new composite is \\ termed as MSF reinforced SAC composite (MSFRSC). The mechanical behaviour of MSFRSC was \\ experimentally investigated, the flexural toughness and ductility of MSFRSC was evaluated. It was found \\ that the compressive strength, flexural strength, shear strength, flexural toughness and ductility of \\ MSFRSC were significantly influenced by the curing time and volume fraction of MSF. The compressive \\ strength, flexural strength and shear strength of MSFRSC increased with the increase of curing time, \\ especially during the first three days. The flexural strength and shear strength of MSFRSC improved \\ significantly with the increase of the volume fraction of MSF. The flexural toughness of MSFRSC \\ significantly improved and the ductility slightly improved with the increase of the volume fraction of MSF \\ from $0.0 \%$ to $2.0 \%$. The flexural toughness slightly increased and the ductility slightly decreased with the \\ increase of the curing time from 1 day to 28 days. Also, the recommendations of different codes for the \\ evaluation of the flexural toughness and ductility of MSFRSC were compared. The recommendations in \\ ASTM C1609 fully reflected the flexural toughness and ductility of MSFRSC. The recommendations in \\ JG/T 472-2015 distinguished the influence of MSF on the pre-peak and post-peak flexural load-deflection \\ behaviours of MSFRSC. A simplified approach based on JG/T 472-2015 was proposed to evaluate the \\ flexural ductility of MSFRSC.

\section{Disciplines} \\ Engineering | Science and Technology Studies

\section{Publication Details} \\ Feng, H., Chen, G., Hadi, M. N. S., Sheikh, M. Neaz. \& Zhou, B. (2018). Mechanical behaviour of micro-fine \\ steel fibre reinforced sulphoaluminate cement composite. Construction and Building Materials, 170 \\ 91-100.
}


2 Mechanical behaviour of micro-fine steel fibre reinforced sulphoaluminate cement composite

4

$5 \quad$ Hu Feng ${ }^{\mathrm{a}}$ Gang Chen $^{\mathrm{b}, \mathrm{c}, *}$ Muhammad N.S. Hadi ${ }^{\mathrm{c}} \quad$ M. Neaz Sheikh ${ }^{\mathrm{c}}$ Bowen Zhou $^{\mathrm{d}}$ 6

7

8

9 10

11

29

30

31
${ }^{\mathrm{a}}$ School of Civil Engineering, Zhengzhou University, Henan, 450001, China

${ }^{\mathrm{b}}$ School of Civil Engineering, Henan University of Engineering, Zhengzhou, Henan 451191, China

\section{${ }^{c}$ School of Civil, Mining and Environmental Engineering, University of Wollongong, NSW} 2522, Australia

${ }^{\mathrm{d}}$ School of Civil Engineering, Tongji University, Shanghai, 200092, China

\section{Correspondence:}

Gang Chen

School of Civil Engineering

Henan University of Engineering, Zhengzhou, Henan 451191, China

E-mail: gchen@haue.edu.cn

Telephone: +8637163885218

* Corresponding author 
Mechanical behaviour of micro-fine steel fibre reinforced sulphoaluminate

\section{cement composite}

Abstract: In this study, a new cement-based composite with high early strength and toughness was developed by the addition of micro-fine steel fibre (MSF) in sulphoaluminate cement (SAC). The new composite is termed as MSF reinforced SAC composite (MSFRSC). The mechanical behaviour of MSFRSC was experimentally investigated, the flexural toughness and ductility of MSFRSC was evaluated. It was found that the compressive strength, flexural strength, shear strength, flexural toughness and ductility of MSFRSC were significantly influenced by the curing time and volume fraction of MSF. The compressive strength, flexural strength and shear strength of MSFRSC increased with the increase of curing time, especially during the first three days. The flexural strength and shear strength of MSFRSC improved significantly with the increase of the volume fraction of MSF. The flexural toughness of MSFRSC significantly improved and the ductility slightly improved with the increase of the volume fraction of MSF from $0.0 \%$ to $2.0 \%$. The flexural toughness slightly increased and the ductility slightly decreased with the increase of the curing time from 1 day to 28 days. Also, the recommendations of different codes for the evaluation of the flexural toughness and ductility of MSFRSC were compared. The recommendations in ASTM C1609 fully reflected the flexural toughness and ductility of MSFRSC. The recommendations in JG/T 472-2015 distinguished the influence of MSF on the pre-peak and post-peak flexural load-deflection behaviours of MSFRSC. A simplified approach based on JG/T 472-2015 was proposed to evaluate the flexural ductility of MSFRSC.

Keywords: Sulphoaluminate cement; Micro-fine steel fibres; Strength; Flexural toughness and ductility 


\section{Research Highlights}

$59 *$ A new cement based composite (MSFRSC) with high early strength and toughness was developed.

$60 *$ The mechanical behaviour of MSFRSC was experimentally investigated.

$61 *$ The flexural and shear strength of MSFRSC were improved by the addition of MSF.

$62 *$ The flexural toughness of MSFRSC was improved significantly by the addition of MSF.

$63 *$ The flexural toughness of MSFRSC was evaluated based on different codes. 


\section{Introduction}

Sulphoaluminate cement (SAC) is well known for its high early strength, fast setting, and high frost and permeation resistance. The SAC has been widely used in the rapid construction and repair of existing structures [1, 2], structures exposed to sub-zero temperature [3], as well as water retaining structures $[4,5]$ in the last few decades. Compared to the ordinary Portland cement (OPC), SAC is green cement with lower $\mathrm{CO}_{2}$ emissions $[6,7,8]$. It uses industrial waste materials during the manufacturing process $[9,10]$. Therefore, $\mathrm{SAC}$ is considered a suitable alternative to $\mathrm{OPC}$ and has the potential for wider applications in the environmentally sustainable construction industry [11].

Significant research attentions have been devoted in recent years on the SAC due to its superior mechanical properties. Ding et al. [12] developed high performance ultra-early strength SAC grout by using superplasticizer, early strength agent and anti-moisture dispersant. The test results showed that SAC grout achieved 8-hour compressive strength of $40 \mathrm{MPa}$ and 28-day compressive strength of 65 MPa. Ma et al. [13] mixed nano- $\mathrm{SiO}_{2}$ into $\mathrm{SAC}$ based composite materials to investigate the flowability and the compressive and flexural strength of the paste. It was found that the compressive and flexural strength of specimens increased and the flowability of paste decreased with the increase of nano- $\mathrm{SiO}_{2}$ content in the paste. The compressive strengths at 8 hours and 28 days were $65.7 \mathrm{MPa}$ and 92.1 MPa, respectively. The flexural strengths at 8 hours and 28 days were $8.5 \mathrm{MPa}$ and $9.4 \mathrm{MPa}$, respectively. Li et al. [14] blended magnesium potassium phosphate cement (MKPT) and calcium sulphoaluminate cement (CSA) to develop a blended system (CSA-MKPT), which was cured in various relative humidity and temperatures. Li et al. [14] investigated the mechanical properties of CSA-MKPT. It was found that the humidity hardly had any effect on the compressive strength of CSA-MKPT. The compressive strengths of CSA-MKPC cured for 7 days with SAC contents of 20\%, $30 \%$ and $40 \%$ of the weight of the $\mathrm{MgO}$ were $78.05 \mathrm{MPa}, 74.75 \mathrm{MPa}$ and $65.73 \mathrm{MPa}$, respectively, at a curing temperature of $-5^{\circ} \mathrm{C}$. Chen et al. [15] developed a new artificial reef concrete (NARC) with SAC, sea sand, sea water and other admixtures. The measured compressive strengths of NARC cured 
for 3 days, 7 days and 28 days were $55.3 \mathrm{MPa}, 63.3 \mathrm{MPa}$ and $71.3 \mathrm{MPa}$, respectively. The compressive strength at 3 days was nearly $80 \%$ of the compressive strength at 28 days.

Although a significant number of studies were carried out on the development of SAC, the SACbased composites are typically brittle in nature. For the OPC concrete, the most effective way of reducing the brittleness and improving the toughness or ductility is the addition of steel fibre (SF) [16] in the concrete mix. Relatively low cost and high effectiveness of steel fibre, especially the micro-fine steel fibre (MSF), in enhancing the performance of concrete, make the MSF an attractive choice for the addition in OPC concrete. The MSF is made of drawn wire and coated with copper. The diameter of MSF usually varies between $0.2 \mathrm{~mm}$ and $0.3 \mathrm{~mm}$. The tensile yield strength is usually more than 2000 MPa. Compared to ordinary SF, MSF has the advantages of having a larger number of fibres per kilo, higher tensile strength and easier dispersion. The MSF was used to prepare the reactive powder concretes with the ultra-high compressive strength of more than $100 \mathrm{MPa}$. The addition of MSF improves tensile strength, flexural strength and ductility of the reactive powder concrete $[17,18,19]$. The effect of MSF on high performance alkali-activated slag/silica fume mortars was investigated by Aydin and Baradan [20]. The test results indicated that the alkali activated matrices achieved higher bond to the MSFs compared to OPC matrices and increase in the fibre content reduced the shrinkage cracking associated with the alkaline activation of slag systems. When MSF was used in engineered cementitious composites with SAC, the cracking strength, tensile strength and maximum tensile strain at failure of the composites were increased. The individual crack width in the multiple-cracking stage was decreased with the addition of MSF [21]. Hence, MSF has the potential to improve the brittleness of SAC composite.

In this study, a new cement-based composite with high early strength and toughness was developed by adding MSF in SAC. The new composite is named as MSF reinforced SAC composite (MSFRSC). The compressive strength, shear strength, flexural strength and flexural performance tests were conducted to investigate the effect of MSF volume fraction, curing time and water-binder ratio on the mechanical behaviour of MSFRSC. Afterward, the flexural behaviour of MSFRSC has been evaluated 
based on the flexural load-midspan deflection curves and the flexural performance index calculated by the recommendations in different standards.

\section{Experimental program}

\subsection{Materials}

The SAC used for all the mixtures was Grade P.O 52.5R according to GB20472-2006 [22]. The properties of cement provided by the manufacturer [23] are reported in Table 1. The natural river sand with the fineness modulus of 2.0 was used as fine aggregate. Silica fume with $\mathrm{SiO}_{2}$ content of $92 \%$ and apparent density of $150-250 \mathrm{~kg} / \mathrm{m}^{3}$ was used as an additional admixture. The Naphthalene sulfonate formaldehyde condensate (FDN) was used as a water reducing agent with a water reducing ratio of $0.18-0.25$. Both ends of the micro-fine steel fibre (MSF) used in this study were deformed, as shown in Fig. 1. The properties of MSF provided by the manufacturer [24] are reported in Table 2.

\subsection{Test parameters and mixture proportions}

The aim of this study is to investigate the effects of MSF volume fraction $\left(\rho_{\mathrm{f}}\right)$, weight ratio of water to binder $(w / b)$ and curing time $(t)$ on the mechanical behaviour of SAC composite. The $w / b$ ratio was taken as $0.22,0.24$ and 0.26 to achieve the target compressive strength of more than $40 \mathrm{MPa}$ at 1 day curing. The MSF volume fraction $\left(\rho_{\mathrm{f}}\right)$ was taken as $0.0 \%, 1.0 \%$ and $2.0 \%$. The curing time $(t)$ was set as 3 hours ( 3 h), 6 hours (6 h), 9 hours ( 9 h), 12 hours (12 h), 1 day ( 1 d), 3 days ( 3 d), 7 days (7 d) and 28 days (28 d) for investigating the early and normal performance of MSF reinforced SAC composite (MSFRSC). Five groups of MSFRSC were used in this study. The mix proportions are listed in Table 3. In the group name in Table 3, A, B and C represent the weight ratio of water to binder $(w / b)$ of $0.22,0.24$ and 0.26 , respectively. Afterward, the number 0,1 and 2 represent the volume fraction of MSF $\left(\rho_{\mathrm{f}}\right)$ of $0.0 \%, 1.0 \%$ and $2.0 \%$, respectively. The binder included cement and 
silica fume. The amount of FDN (Naphthalene sulfonate formaldehyde condensate) in all the groups was $2.0 \%$ of cement by weight.

\subsection{Specimen preparation}

The MSFRSC was mixed using a shaft mixer. At first, SAC, silica fume and sand were mixed in the shaft mixer for 3 minutes. Afterward, MSF was added and mixed for another 3 minutes. Finally, water and FDN were added and mixed for another 5 to 6 minutes to obtain the desired mortar with no segregation. The mixing process of MSFRSC is shown in Fig. 2.

For every curing period, three prism specimens of $40 \mathrm{~mm} \times 40 \mathrm{~mm} \times 160 \mathrm{~mm}$ were cast using steel moulds for the compressive strength and flexure strength tests. Three prism specimens of 100 $\mathrm{mm} \times 100 \mathrm{~mm} \times 300 \mathrm{~mm}$ were cast using plastic moulds for shear strength test. Three prism specimens of $100 \mathrm{~mm} \times 100 \mathrm{~mm} \times 400 \mathrm{~mm}$ were cast using plastic moulds for flexural toughness test. All specimens were vibrated on a vibration table for 30 seconds to ensure adequate compaction. After 1 hour, the specimens were demoulded. Then, the specimens were cured in standard curing room (approximately a relative humidity of $95 \%$ and a temperature of $20^{\circ} \mathrm{C}$ ) until the time of testing.

\subsection{Test procedure}

The compressive strength and flexural strength tests were conducted according to GB/T17671-1999 [25]. A universal testing machine with a capacity of $300 \mathrm{kN}$ was used for the compressive strength and flexural strength tests, as shown in Fig. 3. At first, the $40 \mathrm{~mm} \times 40 \mathrm{~mm} \times 160 \mathrm{~mm}$ prism specimens with the span length of $100 \mathrm{~mm}$ were loaded in the middle to measure the flexural strength. The loading rate was $50 \mathrm{~N} / \mathrm{s}$ (Fig. 3a). Afterward, the two parts of each fractured prism specimen were placed on the test setup with a compression area of $40 \times 40 \mathrm{~mm}$ to test the compressive strength at a loading rate of $2.4 \mathrm{kN} / \mathrm{s}$ (Fig. 3b). 
The $100 \mathrm{~mm} \times 100 \mathrm{~mm} \times 300 \mathrm{~mm}$ prism specimens were tested for shear strength according to JG/T472-2015 [26] by using a universal testing machine with capacity of $500 \mathrm{kN}$, as shown in Fig. 4. The two cross-sections of the prism specimen were sheared at a loading rate of $0.08 \mathrm{MPa} / \mathrm{s}$.

171

The $100 \mathrm{~mm} \times 100 \mathrm{~mm} \times 400 \mathrm{~mm}$ prism specimens were tested for flexural performance (toughness and ductility) according to JG/T472-2015 [26] and ASTM C1609 [27]. The test was conducted by using a universal testing machine with a capacity of $2000 \mathrm{kN}$. The third-point loading was applied on the prism specimen with a loading rate at $0.1 \mathrm{~mm} / \mathrm{min}$. To achieve accurate net deflection at the midspan excluding the effects of seating or twisting of the specimen on its supports, the specimens were surrounded by a rectangular jig. The jig was clamped to the specimen at the mid-depth directly over the supports. Two linear variable displacement transducers (LVDTs) were mounted on the jig at midspan, (one on each side), to measure the midspan deflection (Fig. 5). The average of the two measurements represented the midspan deflection. The load was recorded by a load transducer with a capacity of $100 \mathrm{kN}$. All the readings (load and deflection) were collected by a data logger at every two seconds.

\section{Results and discussion}

\subsection{Compressive and flexural strength}

The average compressive strength $\left(f_{\mathrm{c}}^{\prime}\right)$ and average flexural strength $\left(f_{\mathrm{f}}\right)$ of MSFRSC at the curing time $(t)$ from $3 \mathrm{~h}$ to $28 \mathrm{~d}$ are presented in Table 4 . It can be seen that for the addition of MSF by volume from $0.0 \%$ (Group B0) to $1.0 \%$ (Group B1), the compressive strength of MSFRSC increased by $4.8 \%, 11.8 \%, 11.3 \%$ and $13.9 \%$ for specimens cured for $3 \mathrm{~h}, 12 \mathrm{~h}, 3 \mathrm{~d}$ and $7 \mathrm{~d}$, respectively, as shown in Fig. 6(a). When the addition of MSF by volume increased to 2.0\% (Group B2), the compressive strength of MSFRSC increased by 16.8\%, 18.4\%, $8.8 \%$ and $12.7 \%$ for specimens cured for $3 \mathrm{~h}, 12 \mathrm{~h}, 3 \mathrm{~d}$ and $7 \mathrm{~d}$, respectively. Therefore, the addition of MSF of $1.0 \%$ by volume had the most significant positive effect on the improvement of compressive strength of MSFRSC, especially 
at the curing time of $3 \mathrm{~d}$ and $7 \mathrm{~d}$. The compressive strength of MSFRSC increased significantly for the addition of MSF of $2.0 \%$ by volume at the curing time of $3 \mathrm{~h}$ and $12 \mathrm{~h}$. However, the rate of increase was not higher for the addition of MSF of $2.0 \%$ by volume at the curing time of $3 \mathrm{~d}$ and $7 \mathrm{~d}$ compared to the addition of MSF of $1.0 \%$ by volume, as the addition of MSF of $2.0 \%$ by volume might have caused an uneven distribution or balling of fibres, which partially compromised the reinforcing effect of the fibres.

The addition of MSF significantly improved the flexural strength $\left(f_{\mathrm{f}}\right)$ of MSFRSC, as shown in Fig. 6(b). For the addition of MSF by volume from $0.0 \%$ (Group B0) to $2.0 \%$ (Group B2), the flexural strength of the specimens increased by $72.5 \%, 68.3 \%, 26.1 \%$ and $121.2 \%$ at the curing time of $3 \mathrm{~h}$, $12 \mathrm{~h}, 3 \mathrm{~d}$ and $7 \mathrm{~d}$, respectively. The improvement of the flexural strength was significantly larger than the improvement of the compressive strength. The MSF mainly arrested the propagation of cracks and delayed the onset of cracks and improved the flexural strength of MSFRSC.

For the specimens with the addition of $1.0 \%$ MSF by volume, when water-binder ratio $(w / b)$ increased from 0.22 (Group A1) to 0.26 (Group C1), the compressive strength of the specimens decreased by $31.5 \%, 32.3 \%, 13.1 \%$ and $36.9 \%$ at the curing time of $3 \mathrm{~h}, 12 \mathrm{~h}, 3 \mathrm{~d}$ and $7 \mathrm{~d}$, respectively, as shown in Fig. 7(a). The flexural strength of the specimens also noticeably decreased by $39.4 \%, 30.1 \%, 29.1 \%$ and $25.3 \%$ at the curing time of $3 \mathrm{~h}, 12 \mathrm{~h}, 3 \mathrm{~d}$ and $7 \mathrm{~d}$, respectively, when $w / b$ ratio increased from 0.22 (Group A1) to 0.26 (Group C1), as shown in Fig. 7(b). This indicated that higher $w / b$ ratio reduced the compressive strength and flexural strength of MSFRSC.

With the increase of curing time $(t)$ from $3 \mathrm{~h}$ to $28 \mathrm{~d}$, the specimens showed a continuous increase of the compressive strength and flexural strength for the addition of $1.0 \%$ MSF by volume, especially for the specimens cured for less than $3 \mathrm{~d}$, as shown in Fig. 8. For Group B1 specimens, the compressive strength of the specimen cured for $3 \mathrm{~d}$ was $81.8 \%$ of the compressive strength of the specimen cured for $28 \mathrm{~d}$. Also, the flexural strength of the specimen cured for $3 \mathrm{~d}$ was $71.7 \%$ of the 
221 flexural strength of the specimen cured for $28 \mathrm{~d}$. Group B2 specimens with the addition of $2.0 \%$ MSF

222 by volume showed a similar increase in the compressive and flexural strength as observed for the

223 addition of $1 \%$ MSF by volume for Group B1 specimens. The early development of compressive

224 strength and flexural strength were positively influenced by the fast hydration of SAC.

225

226

3.2. Shear strength

227

The average shear strength $\left(f_{\mathrm{s}}\right)$ of MSFRSC specimens with the addition of MSF from $0.0 \%$ to $2.0 \%$

228 by volume and cured for $1 \mathrm{~d}, 3 \mathrm{~d}$ and $28 \mathrm{~d}$ are shown in Table 5 . It can be observed that the shear strength of MSFRSC increased significantly with the increase of curing time from $1 \mathrm{~d}$ to $28 \mathrm{~d}$. The shear strength of Group B1 specimens with 1.0\% MSF by volume cured for $3 \mathrm{~d}$ attained $81.7 \%$ of the shear strength of specimens cured for $28 \mathrm{~d}$. For Group B2 specimens, the shear strength of specimens with $2.0 \%$ MSF by volume cured for $3 \mathrm{~d}$ attained $73.6 \%$ of that cured for $28 \mathrm{~d}$, as shown in Fig. 9(a). The specimens cured for $3 \mathrm{~d}$, the shear strength increased with the increase of volume fraction of MSF from $0.0 \%$ to $2.0 \%$, as shown in Fig. 9(b). The shear strength of Group B2 specimens was 1.75 times of the shear strength of Group B0 specimens which did not include MSF at curing time of $3 \mathrm{~d}$. The reason for the improvement of shear strength was similar to the reason for the improvement of compressive strength and flexural strength. With the non-uniform distribution fibres across the potential shear damage section, the resistance of shear failure was provided by the cement matrix and fibres. When the shear failure occurred, the fibres were cut or pulled out. The tensile and shear strength of steel fibres are much higher than those of cement matrix. Hence, with the increase of fibre content, the shear resistance provided by the steel fibre increased and the shear strength of the MSFRSC increased. 
Figure 10 presents the flexural load-midspan deflection curves of specimens with $0-2.0 \%$ MSF by

247 volume cured for $1 \mathrm{~d}, 3 \mathrm{~d}$ and $28 \mathrm{~d}$. Due to the absence of MSF, Group B0 specimens cured for $28 \mathrm{~d}$

248 failed suddenly after reaching the peak load. However, Groups B1 and B2 specimens with MSF

249

250

251

252

253

254

255

256

257

258

259

260

261

262

263

264

265

266

267

268

269 showed a ductile failure with a descending post-peak flexural load-midspan deflection branch, representing a ductile response after the peak flexural load. For the addition of MSF of $2.0 \%$ by volume, Group B2 specimens showed greater load carrying capacities than Group B1 specimens with $1.0 \%$ MSF by volume. Moreover, due to the development of bond between MSF and SAC matrix, the reinforcing effect of $1.0 \%$ to $2.0 \%$ MSF by volume increased with increasing curing time $(t)$ from $1 \mathrm{~d}$ to $28 \mathrm{~d}$ (Figure 10). It is noted that the specimens with $1.0 \%$ and $2.0 \%$ MSF by volume at the same curing time showed a similar midspan deflection at the flexural peak load with similar shape of the flexural load-midspan deflection curves. This phenomenon reflects that the effect of increasing MSF influenced the load carrying capacity more than it influenced the ductility.

\subsubsection{Effect of curing time}

Fig. 11 presents the flexural load-midspan deflection curves of specimens with $1.0 \%$ and $2.0 \%$ MSF by volume cured for $1 \mathrm{~d}, 3 \mathrm{~d}$ and $28 \mathrm{~d}$. The increase of the curing time $(t)$ substantially improved the peak flexural load and corresponding midspan deflections, as shown in Fig. 11(a) and 11(b). However, the post-peak descending branches of the flexural load-midspan deflection cures were steeper with the increase of the curing time. Therefore, the longer curing time can increase the load carrying capacity, but may reduce the flexural ductility of MSFRSC.

\subsection{Flexural toughness index}

Four methods recommended by ASTM C1018 [28], ASTM C1609 [27], JSCE SF-4 [29] and JG/T 472-2015 [26] can be used to evaluate the flexural toughness for fibre reinforced composites. Since 
the initial cracking load required by ASTM C1018 is difficult to be captured [30], the other three methods were adopted herein to evaluate the flexural toughness of MSFRSC.

\subsubsection{Flexural toughness and ductility index calculated by ASTM C1609 [27]}

The ASTM C1609 [27] defines the total area under the flexural load-midspan deflection curve up to $L / 150$ ( $L$ is beam span; $L=300 \mathrm{~mm}$ for this test) as flexural toughness $T_{150}^{D}(\mathrm{~N} \cdot \mathrm{mm})$. The equivalent flexural strength ratio $R_{T, 150}^{D}$ can be calculated by Eq. (1):

$$
R_{T, 150}^{D}=\frac{150 T_{150}^{D}}{f_{1} b h^{2}} \times 100 \%
$$

where $f_{1}$ is the first peak flexural strength (MPa); $b$ is the width of the specimen $(b=100 \mathrm{~mm}$ for this test); $h$ is the height of the specimen ( $h=100 \mathrm{~mm}$ for this test). The flexural toughness $T_{150}^{D}$ and the equivalent flexural strength ratio $R_{T, 150}^{D}$ calculated by Eq. (1) for the specimens tested are shown in Table 6 and Fig. 12.

The flexural toughness, $T_{150}^{D}$ reflects the energy absorption capacity of MSFRSC, as shown in Fig. 12. With the increase of the curing time from $1 \mathrm{~d}$ to $28 \mathrm{~d}$, the flexural toughness increased slightly by $11.09 \%$ and $3.25 \%$, respectively for the addition of $1.0 \%$ and $2.0 \%$ MSF by volume. With the increase of the addition of MSF from $1.0 \%$ to $2.0 \%$ by volume, the flexural toughness increased significantly by $38.55 \%, 35.70 \%$ and $28.77 \%$, respectively for $1 \mathrm{~d}, 3 \mathrm{~d}$ and $28 \mathrm{~d}$ curing. At every curing time, Group B2 specimens had much higher $T_{150}^{D}$ than Group B1 specimens, which revealed the important effect of MSF on the flexural toughness $T_{150}^{D}$. 
291 The equivalent flexural strength ratio, $R_{T, 150}^{D}$ of MSFRSC calculated from the test results are shown in

292 Fig. 12. The equivalent flexural strength ratio, $R_{T, 150}^{D}$ of MSFRSC slightly increased by $19.26 \%, 0.87 \%$

293

294

295

296

297

298

299

300

301

302

303

304

305

306

307

308

309

310

311

312

313 and $1.60 \%$, respectively for $1 \mathrm{~d}, 3 \mathrm{~d}$ and $28 \mathrm{~d}$ curing with the increase of the addition of MSF from $1.0 \%$ to $2.0 \%$ by volume. The $R_{T, 150}^{D}$ slightly decreased by $4.69 \%$ and $18.80 \%$, respectively for the addition of $1.0 \%$ and $2.0 \%$ MSF by volume with the increase of the curing time from $1 \mathrm{~d}$ to $28 \mathrm{~d}$. The $R_{T, 150}^{D}$ reflected the flexural ductility of MSFRSC determined by the plump degree (fat or thin) of a flexural load-midspan deflection curve. Thus the $R_{T, 150}^{D}$ did not indicate the height (tall or short) of the curve, i.e., peak load or flexural strength. Therefore, the flexural ductility of MSFRSC slightly increased with the increase of the addition of MSF by volume and slightly decreased with the increase of the curing time from $1 \mathrm{~d}$ to $28 \mathrm{~d}$. It is noted that the $R_{T, 150}^{D}$ combined with $T_{150}^{D}$ can fully describe the flexural performance (ductility and toughness) of MSFRSC.

3.4.2. Flexural toughness index calculated by JSCE SF-4 [29].

The definition of flexural toughness specified in JSCE SF-4 [29] is the same as the definition of the flexural toughness specified in ASTM C1609 [27]. The flexural toughness factor ( $F T$ ) according to JSCE SF-4 [29] can be obtained by Eq. (2):

$$
F T=\frac{A_{(L / 150)} L}{(L / 150) b h^{2}}
$$

where $A_{(L / 150)}$ is the flexural toughness, N.mm; $L$ is the span length, $\mathrm{mm} ; b$ is the width of the specimen, $\mathrm{mm} ; h$ is the height of the specimen, $\mathrm{mm}$.

Table 7 and Fig. 13 illustrate the flexural toughness and flexural toughness factor based on JSCE SF-4.

It is evident that the flexural toughness, $A_{(L / 150)}$ and the flexural toughness factor, $F T$ followed the similar order. 
315 In order to make a clear comparison, Eq. (2) can be written as Eq. (3):

$$
F T=\frac{150 A_{(L / 150)}}{f_{1} b h^{2}} f_{1}=R_{T, 150}^{D} \times f_{1}
$$

The $F T$ is a comprehensive index combining the ductility index, $R_{T, 150}^{D}$, calculated according to the

ASTM C1609 [27] and flexural strength, $f_{1}$. Therefore, FT is unable to independently reflect the ductility and it is similar to the flexural toughness. Also, the total area under the curve up to the end point deflection $(L / 150)$ was used to calculate the flexural toughness of MSFRSC, which was unable to distinguish between the pre-peak and post-peak flexural load-midspan deflection behaviours.

In order to distinguish the effect of the addition of fibre on the pre-peak and post-peak flexural loaddeflection behaviours, a new method is recommended by JG/T 472-2015 [26]. In JG/T 472-2015 [26],

$$
f_{\mathrm{e}, \mathrm{p}}=\frac{\Omega_{\mathrm{p}} L}{b h^{2} \delta_{\mathrm{p}}}
$$

$$
R_{\mathrm{e}, \mathrm{p}}=\frac{f_{\mathrm{e}, \mathrm{p}}}{f_{\mathrm{ftm}}}
$$

$$
f_{\mathrm{e}, \mathrm{k}}=\frac{\Omega_{\mathrm{p}, \mathrm{k}} L}{b h^{2}\left(L / k-\delta_{\mathrm{p}, \mathrm{k}}\right)}
$$

$$
R_{\mathrm{e}, \mathrm{k}}=\frac{f_{\mathrm{e}, \mathrm{k}}}{f_{\mathrm{ftm}}}
$$


where $\delta_{\mathrm{p}}$ is the midspan deflection at peak flexural load, $\mathrm{mm} ; \Omega_{\mathrm{p}}$ is the pre-peak flexural toughness (the pre-peak area under the flexural load-deflection curve up to $\delta_{\mathrm{p}}$ ), N.mm; $L$ is the span length, $\mathrm{mm} ; b$ is the width of the specimen, $\mathrm{mm} ; h$ is the height of the specimen $\mathrm{mm} ; f_{\mathrm{ftm}}$ is the flexural strength, MPa; $\Omega_{\mathrm{p}, \mathrm{k}}$ is the post-peak flexural toughness (the post-peak area under the flexural loaddeflection curve between $\delta_{\mathrm{p}}$ to $L / k, k=500,300,250,200$ and 150). The $R_{\mathrm{e}, \mathrm{p}}$ and $R_{\mathrm{e}, \mathrm{k}}$ can reflect the degree to which the fibre changes the pre-peak and post-peak behaviours, respectively, of MSFRSC.

Table 8 and Fig. 14 present the test results calculated based on JG/T 472-2015 [26]. The residual toughness index $R_{\mathrm{e}, \mathrm{k}}\left(R_{\mathrm{e}, 500}, R_{\mathrm{e}, 300}, R_{\mathrm{e}, 250}, R_{\mathrm{e}, 200}\right.$ and $\left.R_{\mathrm{e}, 150}\right)$ showed almost the same order and are nearly in line with the order of $R_{T, 150}^{D}$ calculated according to ASTM C1609 [27]. The $R_{\mathrm{e}, \mathrm{k}}$ effectively reflected the ductility, but not the energy absorption.

The deflection-hardening behaviour of MSFRSC specimens was observed for the midspan deflection between 0 to approximately $0.5 \mathrm{~mm}$. As shown in Fig. 14 and Table 8, the $R_{\mathrm{e}, 500}$ of Group B2-1 d and Group B1-3 d was greater than 1.0, which revealed the deflection-hardening behaviour of MSFRSC and explained the little difference of $R_{\mathrm{e}, \mathrm{k}}$ for $k=500$ and $R_{\mathrm{e}, \mathrm{k}}$ for $k=300,250,200$ and 150 . For this method, the flexural toughness indices were calculated at some specified deflections $(L / k$, $k=500,300,250,200$ and 150 ). However, the calculation of flexural toughness index at various deflections was a complex and time-consuming procedure. As shown in Fig. 14 and Table 8, when $k=300,250,200$ and $150, R_{\mathrm{e}, \mathrm{k}}$ showed a consistent tendency. Therefore, the $k$ can be considered as $\mathrm{k}=500$ and $\mathrm{k}=150$. The flexural toughness index, $R_{\mathrm{e}, \mathrm{k}}$ for $k=500$ reflected the ductility at a minor deflection (less than $0.6 \mathrm{~mm}$ ) and it also reflected the deflection-hardening behaviour of 
MSFRSC. The flexural toughness index, $R_{\mathrm{e}, \mathrm{k}}$ for $k=150$ reflected the overall ductility of MSFRSC at a major deflection $(2.0 \mathrm{~mm})$.

\section{Conclusions}

359
The mechanical behaviour of micro-fine steel fibre (MSF) reinforced sulphoaluminate cement (SAC) composite (MSFRSC) with varying water-binder ratios, curing time and MSF volume fractions has been experimentally investigated. Also, the flexural performance of MSFRSC has been evaluated according to the recommendations of three codes. Based on the experimental and analytical investigations, the following conclusions can be drawn:

(1) Due to the fast hydration, the compressive, flexural and shear strength of MSFRSC were significantly improved with the increase of the curing time, especially in the first 3 days.

(2) The addition of MSF slightly improved the compressive strength of MSFRSC. With the increase of addition of MSF from $0.0 \%$ to $2.0 \%$ by volume, the effect of fibre obstructing cracks increased. The flexural and shear strength of MSFRSC were improved significantly, and the improvement of the flexural and shear strength was higher than the improvement of the compressive strength. Meanwhile, the increase of the addition of MSF was found to be beneficial for the improvement of early compressive strength.

(3) The increasing water-binder ratio from 0.22 to 0.26 resulted in a decrease of the compressive and flexural strength of MSFRSC.

(4) The failure mode changed from brittle to ductile by the addition of MSF. With the increase of the addition of MSF from $0.0 \%$ to $2.0 \%$ by volume, the flexural toughness of MSFRSC increased significantly and the ductility increased slightly. With the increase of the curing time from 1 day to 28 days, the flexural toughness of MSFRSC increased slightly but the ductility decreased slightly. 
379 (5) The recommendations in ASTM C1609 [27] fully reflected the flexural toughness and flexural 380 ductility of MSFRSC. The evaluating results of the flexural toughness of MSFRSC according to 381 the flexural toughness factor $(F T)$ in JSCE SF-4 [29] were similar to that according to the flexural toughness $\left(T_{150}^{D}\right)$ in ASTM C1609 [27]. The recommendations of JG/T 472-2015 [26] distinguished the influence of the addition of MSF on the pre-peak and post-peak flexural loadmidspan deflection behaviours of MSFRSC. Also, the recommendations of JG/T 472-2015 [26] reflected the deflection-hardening behaviour by defining a flexural toughness index at a minor deflection.

\section{Acknowledgments}

388 The first and second authors would like to acknowledge the University of Wollongong, Australia, and the China Scholarship Council for supporting their overseas research scholarship. All the authors acknowledge the University of Wollongong, Australia for providing research foundation. Financial support from National Natural Science Foundation of China (Grant No. 51308504) and Scientific \& Technological Project of Henan Province (152102310068) are gratefully acknowledged. 


\section{References}

395

396

397

398

399

400

401

402

403

404

405

406

407

408

409

410

411

412

413

414

415

416

417

418

419

420

421

422

423

424

425

426

427

428

429

[1] G. Cai, J. Zhao. Application of sulphoaluminate cement to repair deteriorated concrete members in chloride ion rich environment-A basic experimental investigation of durability properties, KSCE J Civ. Eng. 20(7) (2016) 2832-2841.

[2] J. Qian, C. You, Q. Wang, H. Wang, X. Jia. A method for assessing bond performance of cementbased repair materials, Constr. Build. Mater. 68 (2014)307-313.

[3] C.-K. Park. Hydration and solidification of hazardous wastes containing heavy metals using modified cementitious materials, Cement Concr. Res. 30 (3) (2000) 429-435.

[4] T. Kuryatnyk, M. Chabannet, J. Ambroise, J. Pera. Leaching behaviour of mixtures containing plaster of Paris and calcium sulphoaluminate clinker, Cement Concr. Res. 40 (8) (2010) 1149-1156.

[5] T. Kuryatnyk, M. Chabannet, J. Ambroise, J. Pera. Improvement of calcium sulphate water resistance by addition of calcium sulphoaluminate clinker, Mater. Lett. 62 (21-22) (2008) 3713-3715.

[6] M. Singh, P.C. Kapur, Pradip. Preparation of calcium sulphoaluminate cement using fertiliser plant wastes, J. Hazard. Mater. 157 (1) (2008) 106-113.

[7] G. Velazco, J.M. Almanza, D.A. Cortés, J.C. Escobedo, J.I. Escalante-Garcia. Effect of citric acid and the hemihydrate amount on the properties of a calcium sulphoaluminate cement, Mater. Construcc. 64 (316) (2014) 1-8.

[8] E. Gartner. Industrially interesting approaches to "low-CO2" cements, Cement Concr. Res. 34 (9) (2004) 1489-1498.

[9] S. Sahu, J. Majling. Preparation of sulphoaluminate belite cement from fly ash, Cement Concr. Res. 24 (6) (1994) 1065-1072.

[10] L. Pelletier-Chaignat, F. Winnefeld, B. Lothenbach, C.J. Müller. Beneficial use of limestone filler with calcium sulphoaluminate cement, Constr. Build. Mater. 26(1) (2012) 619-627.

[11] M. Juenger, F. Winnefeld, J.L. Provis, J. Ideker. Advances in alternative cementitious binders, Cement Concr. Res. 41 (12) (2011) 1232-1243.

[12] Q. Ding, L. He, Y. Liang, Y. Wang, H. Huang. Ultra-early strength expensive high performance grout, Journal of Wuhan University of Technology (Transportation Science and Engineering), 38(3) (2014)498-501.

[13] B. Ma, H. Li, J. Mei, X. Li. Influence of nano-SiO 2 addition on properties of sulphoaluminate cement based material, Journal of Wuhan University of Technology-Mater. Sci. Ed. 32 (1)(2017)106112.

[14] G. Li, J. Zhang, G. Zhang. Mechanical property and water stability of the novel CSA-MKPC blended system, Constr. Build. Mater. 136 (2017) 99-107.

[15] C. Chen, T. Ji, Y. Zhuang, X. lin. Workability, mechanical properties and affinity of artificial reef concrete, Constr. Build. Mater. 98 (2015) 227-236.

[16] A. Bhutta, P.H.R. Borges, C. Zanotti, M Farooq, N Banthia. Flexural behavior of geopolymer 
composites reinforced with steel and polypropylene macro fibers, Cem. Concr. Compos. 80 (2017) $31-40$.

432 [17] P. Richard, M. Cheyrezy. Composition of reactive powder concretes, Cement Concr. Res. 25(7) (1995) 1501-1511.

[18] A. Cwirzen, V. Penttala, C. Vornanen. Reactive powder based concretes: Mechanical properties, durability and hybrid use with OPC, Cement Concr. Res. 38(10) (2008) 1217-1226. [19] CS (Chinese Standard) GB/T 31387-2015, Reactive Powder Concretes, General Administration of Quality Supervision, Inspection and Quarantine of the People's Republic of China, Standardization Administration of the People's Republic of China, 2015 (in Chinese). [20] S. Aydin, B. Baradan. The effect of fiber properties on high performance alkali-activated slag/silica fume composites, Compos. Part B: Eng. 45(1) (2013) 63-69.

[21] J. Zhang, Q. Wang, Z. Wang. Properties of polyvinyl alcohol-steel hybrid fiber-reinforced composite with high-strength cement matrix, J. Mater. Civ. Eng. 29(7) (2017) 1-9. [22] CS (Chinese Standard) GB 20472-2006, Sulphoaluminate cement, General Administration of Quality Supervision, Inspection and Quarantine of the People's Republic of China, Standardization Administration of the People's Republic of China, 2006 (in Chinese).

446 [23] CS (Chinese Standard) GB/T 17671-1999, Cement mortar strength testing method (ISO), 447 Administration of Quality Supervision of the People 's Republic of China, 1999 (in Chinese).

448 [24] Yicheng Anda Special Cement Co., Ltd. Group. Banqiaodian Town, Yicheng, Hubei, China. http://www.hbadtzsn.com/yewu/36.html/ (Accessed on March 2017) (in Chinese)

450 [25] Shanghai Realstrong Steel Fibre Co., Ltd. 365 Wang Ln, Jinze Town, Shanghai, China. http://www.realstrong.cn/cn/product151.asp (Accessed on March 2017) [26] CS (Chinese Standard) JG/T 472-2015, Steel Fibre Reinforced Concrete, Ministry of Housing and Urban-Rural Development People's Republic China, 2015 (in Chinese).

454 [27] ASTM C1609/C1609M-12, Standard Test Method for Flexural Performance of Fiber-Reinforced 455 Concrete (Using Beam with Third-Point Loading), ASTM International, West Conshohocken, PA, 456 2012, www.astm.org.

457 [28] ASTM C1018-97, Standard Test Method for Flexural Toughness and First-Crack Strength of Fiber-Reinforced Concrete (Using Beam with Third-Point Loading) (Withdrawn 2006), ASTM International, West Conshohocken, PA, 1997, www.astm.org.

460 [29] JSCE Standard SF-4, Method of test for flexural strength and flexural toughness of fibre reinforced concrete, Japan Soc. Civ. Eng. (1984). [30] D. Gao, L. Zhao, H. Feng, S. Zhao. Flexural toughness and it's evaluation method of steel fiber reinforced concrete, Journal of Building Materials (Jianzhu Cailiao Xuebao). 17 (5)(2014) 783-789 464 (in Chinese). 
467 Table 1 Properties of SAC

468 Table 2 Properties of MSF

469 Table 3 Mix proportions of MSFRSC

470 Table 4 Average compressive strength and average flexural strength

471 Table 5 Average shear strength

472 Table 6 Flexural toughness and ductility index according to ASTM C1609 [27]

473 Table 7 Flexural toughness index according to JSCE SF-4 [29]

474 Table 8 Flexural toughness index according to JG/T 472-2015 [26] 
476 Fig. 1 Micro-fine steel fibres

477 Fig. 2 Mixing process of MSFRSC mixtures

478 Fig. 3 Compressive and flexural strength tests

479 Fig. 4 Shear strength test

480 Fig. 5 Flexural toughness test

481 Fig. 6 Effect of volume fraction of MSF on: (a) average compressive strength, $f_{c}^{\prime}$ and (b) average

482 flexural strength, $f_{\mathrm{f}}$

483 Fig. 7 Effect of water-binder ratios on: (a) average compressive strength, $f_{c}^{\prime}$ and (b) average flexural 484 strength, $f_{\mathrm{f}}$

485 Fig. 8 Average compressive strength, $f_{\mathrm{c}}^{\prime}$ and average flexural strength, $f_{\mathrm{f}}$ with varying curing time, $486 t$

487 Fig. 9 Average shear strength, $f_{\mathrm{s}}$ with varying (a) curing time, $t$ and (b) MSF volume fractions, $\rho_{\mathrm{f}}$

488 Fig. 10 Flexural load-midspan deflection curves of specimens with the addition of MSF by volume at 489 curing time: (a) $1 \mathrm{~d}$, (b) $3 \mathrm{~d}$ and (c) $28 \mathrm{~d}$

490 Fig. 11 Flexural load-midspan deflection curves of specimens with varying curing time added MSF:

491 (a) $1.0 \%$ and (b) $2.0 \%$ by volume

492 Fig. 12 Flexural toughness and ductility index according to ASTM C1609 [27]

493 Fig. 13 Flexural toughness index according to JSCE SF-4 [29]

494 Fig. 14 Flexural toughness index according to JG/T 472-2015 [26]

495 
496 Table 1

497 Properties of SAC [24]

\begin{tabular}{|c|c|c|c|c|c|c|c|c|c|c|}
\hline \multirow[t]{2}{*}{$w / c$} & \multirow[t]{2}{*}{$s / c$} & \multicolumn{2}{|c|}{$\begin{array}{l}\text { Compressive } \\
\text { strength } \\
(\mathrm{MPa})\end{array}$} & \multicolumn{2}{|c|}{$\begin{array}{c}\text { Flexural } \\
\text { strength } \\
\text { (MPa) }\end{array}$} & \multicolumn{2}{|c|}{$\begin{array}{l}\text { Setting time } \\
\quad(\min )\end{array}$} & \multirow{2}{*}{$\begin{array}{l}\text { Surface } \\
\text { area } \\
\left(\mathrm{m}^{2} / \mathrm{kg}\right)\end{array}$} & \multirow{2}{*}{$\begin{array}{c}\text { Normal } \\
\text { consistency }\end{array}$} & \multirow{2}{*}{$\begin{array}{c}\text { Free } \\
\text { calcium } \\
\text { oxide }\end{array}$} \\
\hline & & $1 \mathrm{~d}$ & $3 d$ & $1 \mathrm{~d}$ & $3 d$ & $\begin{array}{l}\text { Initial } \\
\text { setting }\end{array}$ & $\begin{array}{c}\text { Final } \\
\text { setting }\end{array}$ & & & \\
\hline 0.45 & 3.0 & 43.8 & 55.9 & 6.6 & 7.1 & 27 & 32 & 455 & $24 \%$ & $0 \%$ \\
\hline
\end{tabular}

498 Note: $w / c$ is the weight ratio of water to cement and $s / c$ is the weight ratio of sand to cement

499 Mechanical properties were determined according to GB/T 17671-1999 [23]. 
500 Table 2

501 Properties of MSF [25]

\begin{tabular}{ccccc}
\hline $\begin{array}{c}\text { Equivalent diameter } \\
(\mathrm{mm})\end{array}$ & Length $(\mathrm{mm})$ & Aspect ratio & $\begin{array}{c}\text { Tensile strength } \\
(\mathrm{MPa})\end{array}$ & Number per kilo \\
\hline 0.22 & 13 & 60 & 2850 & 224862 \\
\hline
\end{tabular}

502 
504 Mix proportions of MSFRSC

\begin{tabular}{cccccccc}
\hline Group & $w / b$ & $\begin{array}{c}\text { Fibre volume } \\
\text { fraction } \rho_{\mathrm{f}}\end{array}$ & Cement & Water & Silica fume & Sand & FDN \\
\hline A1 & 0.22 & $1.0 \%$ & 1 & 0.242 & 0.1 & 1.2 & 0.02 \\
B0 & 0.24 & $0.0 \%$ & 1 & 0.264 & 0.1 & 1.2 & 0.02 \\
B1 & 0.24 & $1.0 \%$ & 1 & 0.264 & 0.1 & 1.2 & 0.02 \\
B2 & 0.24 & $2.0 \%$ & 1 & 0.264 & 0.1 & 1.2 & 0.02 \\
C1 & 0.26 & $1.0 \%$ & 1 & 0.286 & 0.1 & 1.2 & 0.02 \\
\hline
\end{tabular}

505 Note: All numbers are weight ratios to cement except fibre contents (volume fraction). The $w / b$ is 506 the weight ratio of water to binder and FDN is naphthalene sulfonate formaldehyde condensate. 
509 Average compressive strength and average flexural strength

\begin{tabular}{|c|c|c|c|c|c|c|c|c|}
\hline \multirow{2}{*}{ Group } & \multicolumn{8}{|c|}{ Average compressive strength $\left(f_{\mathrm{c}}^{\prime}\right) /$ Average flexural strength $\left(f_{\mathrm{f}}\right) \quad(\mathrm{MPa})$} \\
\hline & $3 \mathrm{~h}$ & $6 \mathrm{~h}$ & $9 \mathrm{~h}$ & $12 \mathrm{~h}$ & $1 \mathrm{~d}$ & $3 d$ & $7 \mathrm{~d}$ & $28 \mathrm{~d}$ \\
\hline A1 & 18.1/7.1 & & & $43.0 / 10.3$ & & $81.9 / 11.0$ & $85.0 / 16.6$ & \\
\hline B0 & $16.7 / 4.0$ & & & $38.0 / 6.3$ & & $73.5 / 9.2$ & $79.0 / 8.2$ & \\
\hline B1 & $17.5 / 4.6$ & $25.4 / 5.0$ & $32.0 / 6.0$ & $42.5 / 7.4$ & $55.0 / 8.95$ & $81.8 / 10.4$ & $90.0 / 12.4$ & $100.0 / 14.5$ \\
\hline B2 & $19.5 / 6.9$ & & & $45.0 / 10.6$ & & $80.0 / 11.6$ & $89.0 / 17.4$ & \\
\hline $\mathrm{C} 1$ & $12.4 / 4.3$ & & & $29.1 / 7.15$ & & $71.2 / 7.8$ & $53.6 / 12.5$ & \\
\hline
\end{tabular}


$510 \quad$ Table 5

511 Average shear strength

\begin{tabular}{cccc}
\hline \multirow{3}{*}{ Group } & \multicolumn{3}{c}{ Average shear strength $\left(f_{\mathrm{s}}\right)(\mathrm{MPa})$} \\
\cline { 2 - 4 } & $1 \mathrm{~d}$ & $3 \mathrm{~d}$ & $28 \mathrm{~d}$ \\
\hline B0 & & 5.9 & \\
B1 & 6.0 & 7.6 & 9.3 \\
B2 & 8.7 & 10.3 & 14.0 \\
\hline
\end{tabular}


512 Table 6

513 Flexural toughness and ductility index according to ASTM C1609 [28]

\begin{tabular}{cccc}
\hline Group & Curing time & $\begin{array}{c}\text { Flexural toughness } \\
T_{150}^{D}(\mathrm{kN} \cdot \mathrm{mm})\end{array}$ & $\begin{array}{c}\text { Equivalent flexural strength ratio } \\
R_{T, 150}^{D}(\%)\end{array}$ \\
\hline B1 & $1 \mathrm{~d}$ & 19.12 & 71.66 \\
B2 & $1 \mathrm{~d}$ & 26.49 & 85.46 \\
B1 & $3 \mathrm{~d}$ & 20.31 & 75.49 \\
B2 & $3 \mathrm{~d}$ & 27.56 & 76.15 \\
B1 & $28 \mathrm{~d}$ & 21.24 & 68.30 \\
B2 & $28 \mathrm{~d}$ & 27.35 & 69.39 \\
\hline
\end{tabular}

514

Note: the reported values are the average value for each Group.

515 
$516 \quad$ Table 7

517 Flexural toughness index according to JSCE SF-4 [29]

\begin{tabular}{cccc}
\hline Group & Curing time & $\begin{array}{c}\text { Flexural toughness } \\
A_{(L / 150)}(\mathrm{kN} \cdot \mathrm{mm})\end{array}$ & $\begin{array}{c}\text { Flexural toughness factor } \\
F T(\mathrm{MPa})\end{array}$ \\
\hline B1 & $1 \mathrm{~d}$ & 19.12 & 2.86 \\
B2 & $1 \mathrm{~d}$ & 26.49 & 3.97 \\
B1 & $3 \mathrm{~d}$ & 20.31 & 3.04 \\
B2 & $3 \mathrm{~d}$ & 27.56 & 4.13 \\
B1 & $28 \mathrm{~d}$ & 21.24 & 3.18 \\
B2 & $28 \mathrm{~d}$ & 27.35 & 4.10 \\
\hline
\end{tabular}

518 Note: the reported values are the average value for each Group. 
519 Table 8 Flexural toughness index according to JG/T 472-2015 [26]

\begin{tabular}{cccccccc}
\hline $\begin{array}{c}\text { Group } \\
\text { Curing } \\
\text { time }\end{array}$ & $R_{\mathrm{e}, \mathrm{p}}(L / k=0.6 \mathrm{~mm})(L / k=1.0 \mathrm{~mm})(L / k=1.2 \mathrm{~mm})(L / k=1.5 \mathrm{~mm})(L / k=2.0 \mathrm{~mm})$ \\
\hline B1 & $1 \mathrm{~d}$ & 0.86 & 0.95 & 0.89 & 0.85 & 0.79 & 0.71 \\
B2 & $1 \mathrm{~d}$ & 0.89 & 1.02 & 0.98 & 0.96 & 0.92 & 0.85 \\
B1 & $3 \mathrm{~d}$ & 0.88 & 1.03 & 0.96 & 0.91 & 0.84 & 0.75 \\
B2 & $3 \mathrm{~d}$ & 0.92 & 0.99 & 0.92 & 0.88 & 0.83 & 0.76 \\
B1 & $28 \mathrm{~d}$ & 0.84 & 0.97 & 0.88 & 0.84 & 0.77 & 0.68 \\
B2 & $28 \mathrm{~d}$ & 0.76 & 0.97 & 0.87 & 0.83 & 0.78 & 0.69 \\
\hline
\end{tabular}

520 Note: $R_{\mathrm{e}, \mathrm{p}}$ is the initial toughness index; $R_{\mathrm{e}, \mathrm{k}}$ is the residual toughness index corresponding to the 521 midspan deflection of $L / k$ (where $k=500,300,250,200$ and 150) and $L$ is the span length.

522 The reported values are the average value for each Group. 


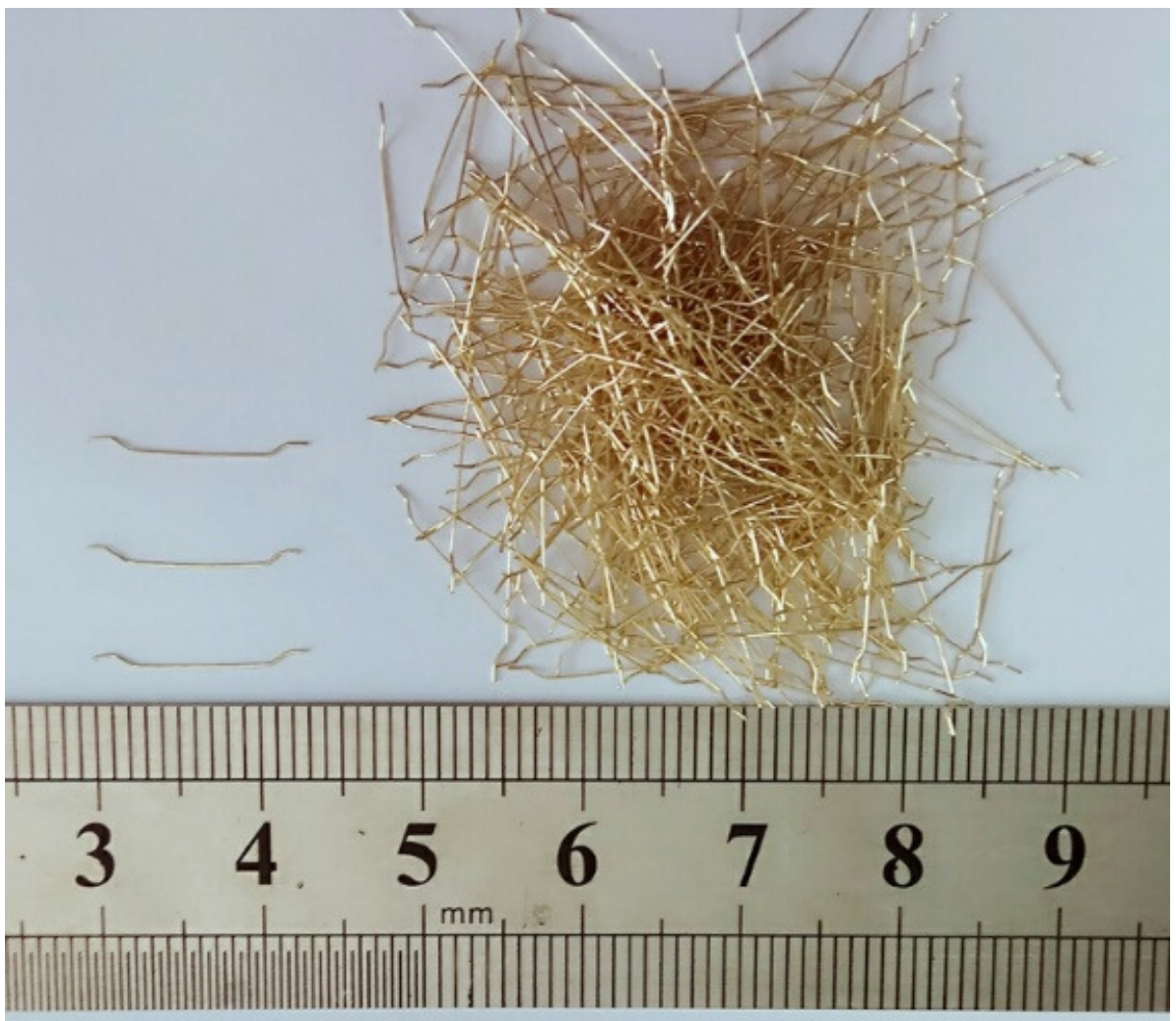

Fig. 1 Micro-fine steel fibres 


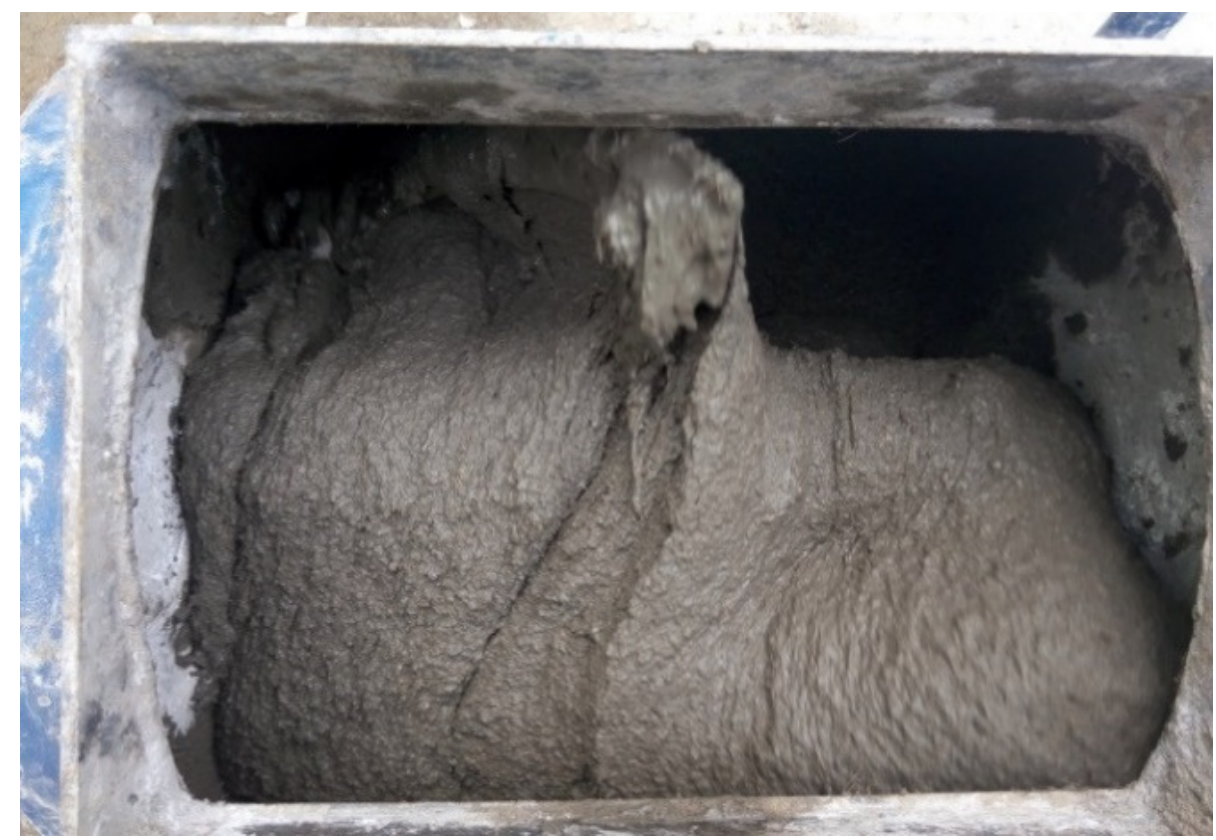

527

Fig. 2 Mixing process of MSFRSC mixture 


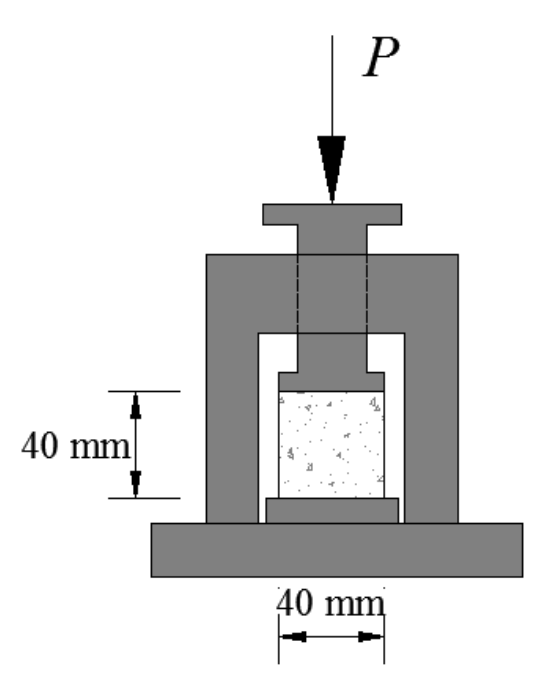

(b)

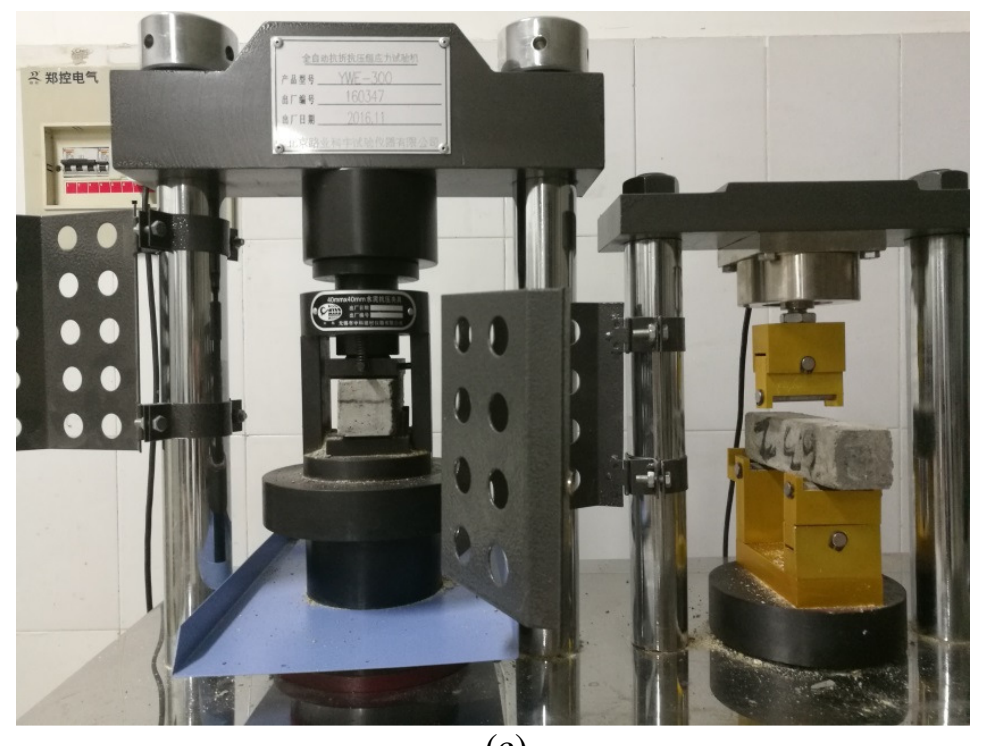

(c)

Fig. 3 Compressive and flexural strength test:

(a) Schematic representation of flexural strength, (b) Schematic representation of compressive strength and (c) Photo of the test 


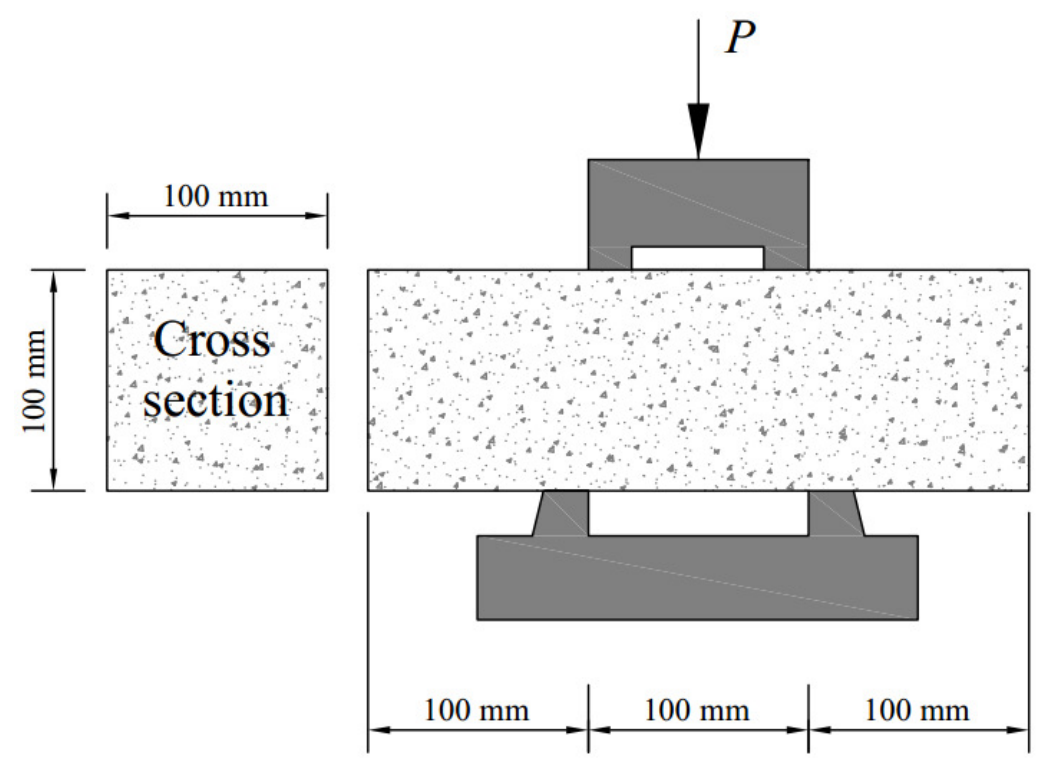

(a)

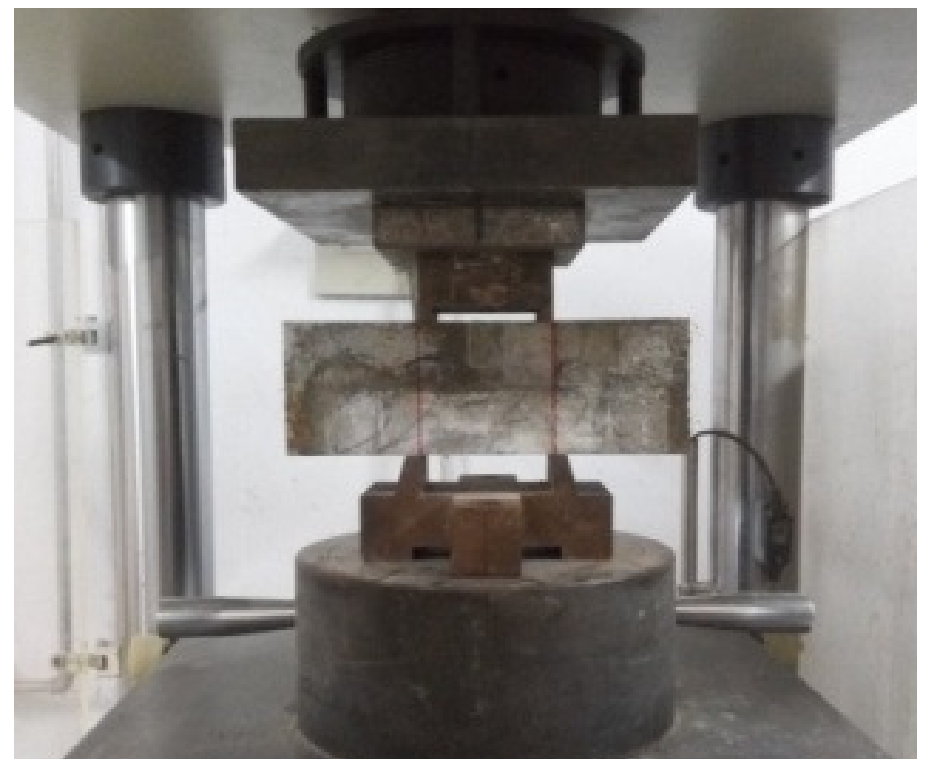

(b)

Fig. 4 Shear strength test: (a) Schematic representation and (b) Photo of the shear strength test 


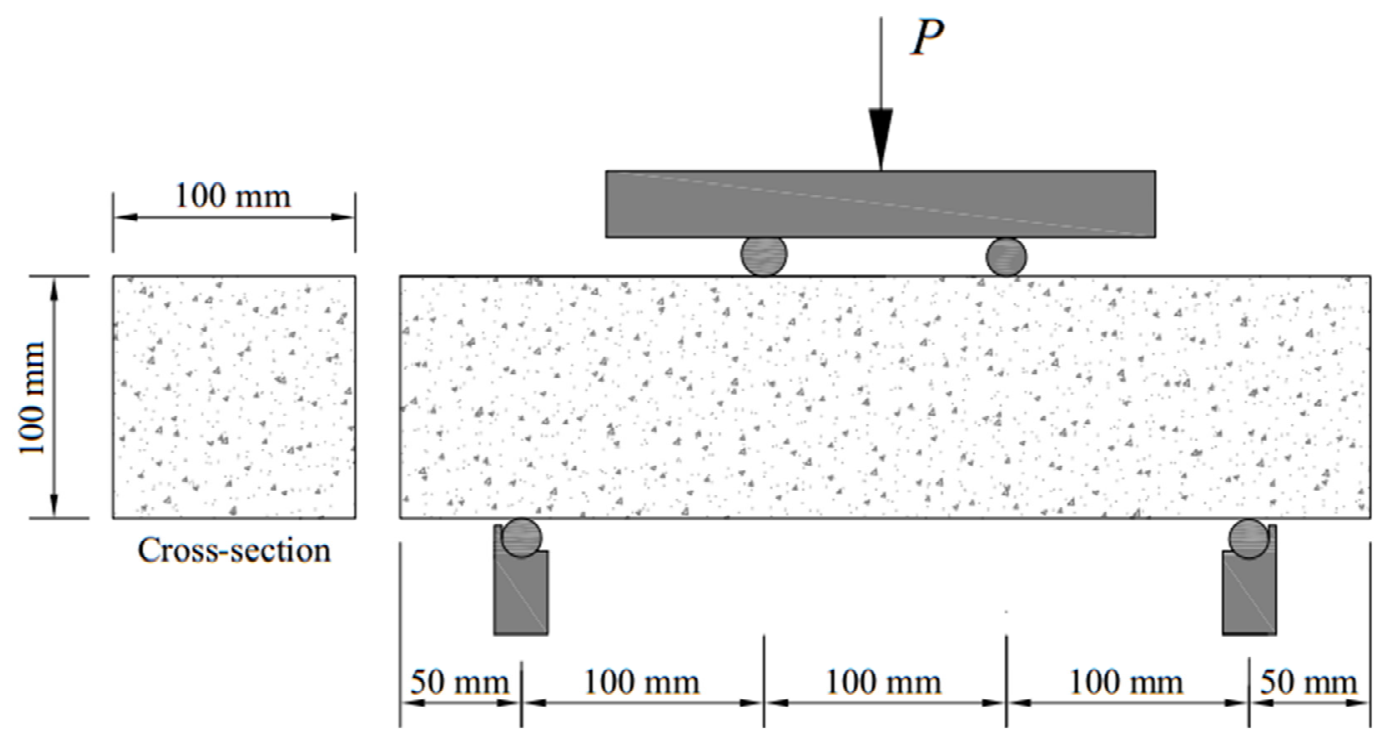

(a)

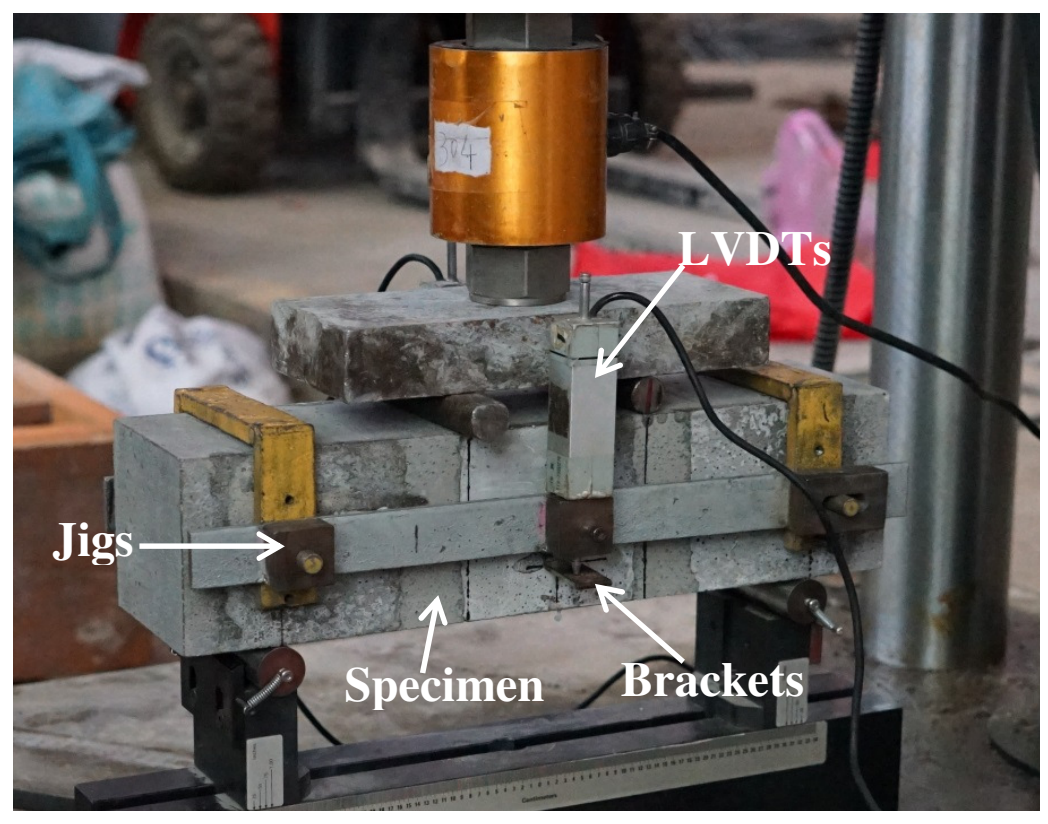

(b)

Fig. 5 Flexural toughness test: (a) Schematic representation and (b) Photo of the test 


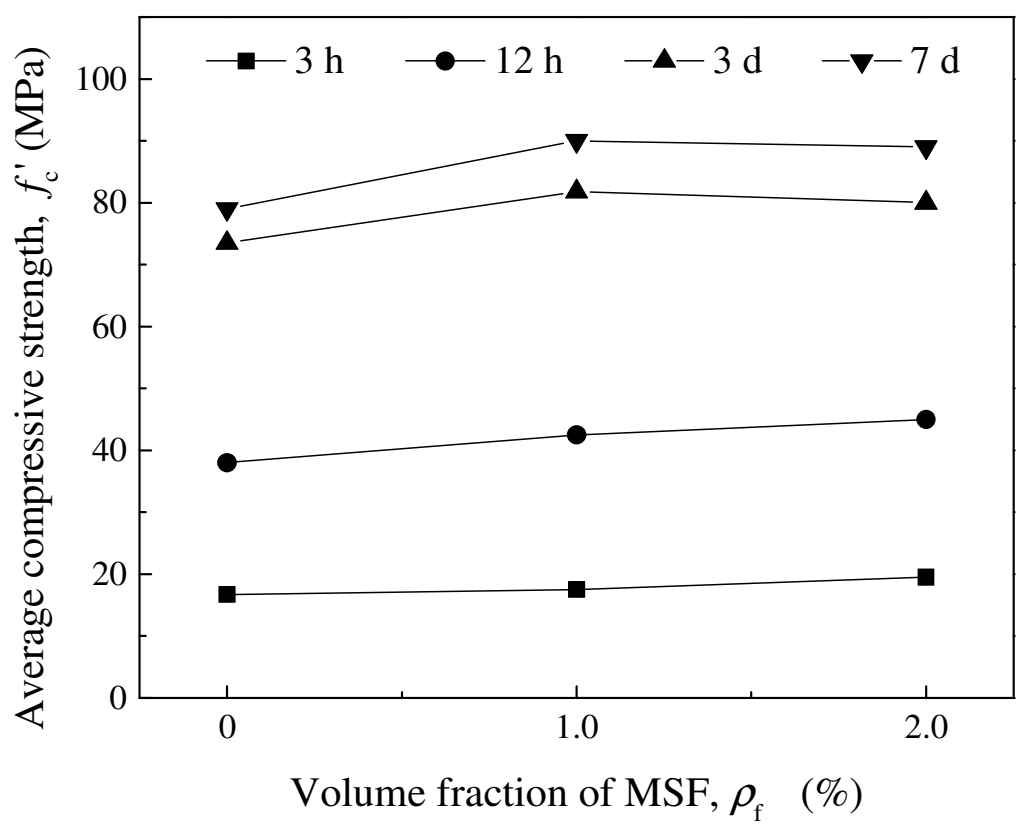

541

(a)

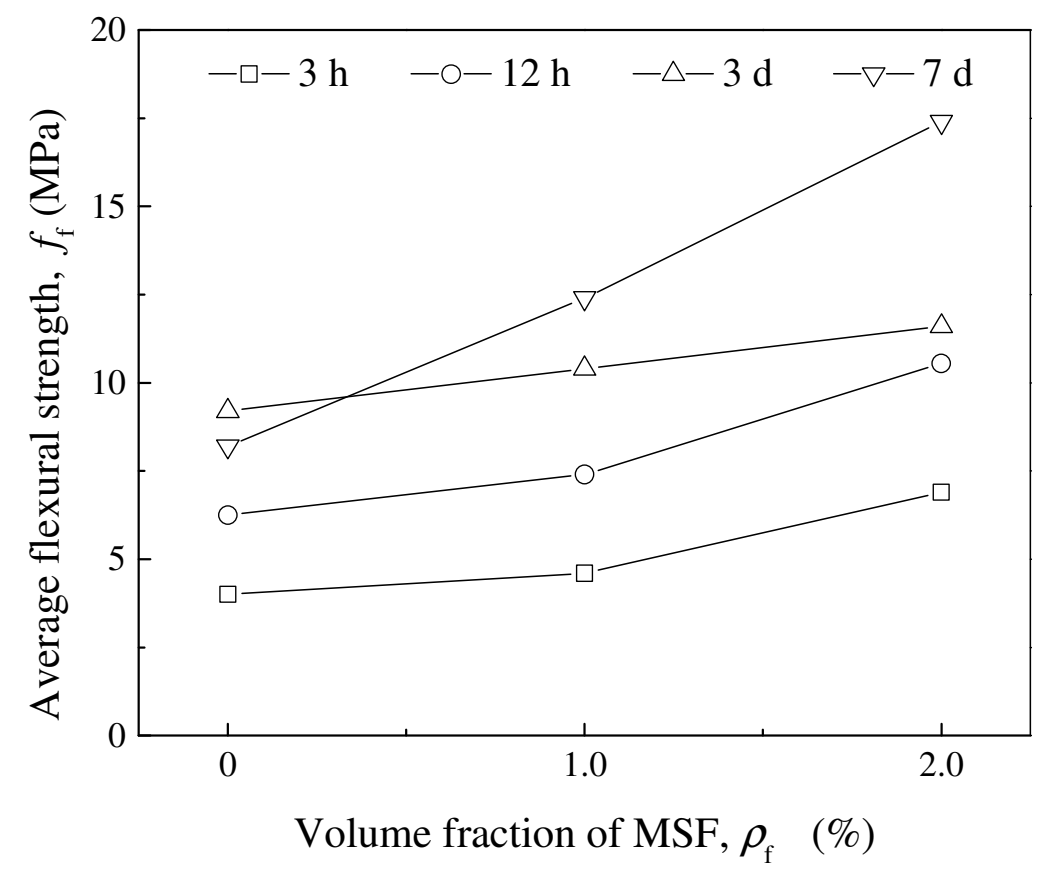

(b)

544 Fig. 6 Effect of volume fraction of MSF on: (a) average compressive strength, $f_{c}^{\prime}$ and (b) average 545 flexural strength, $f_{\mathrm{f}}$ 


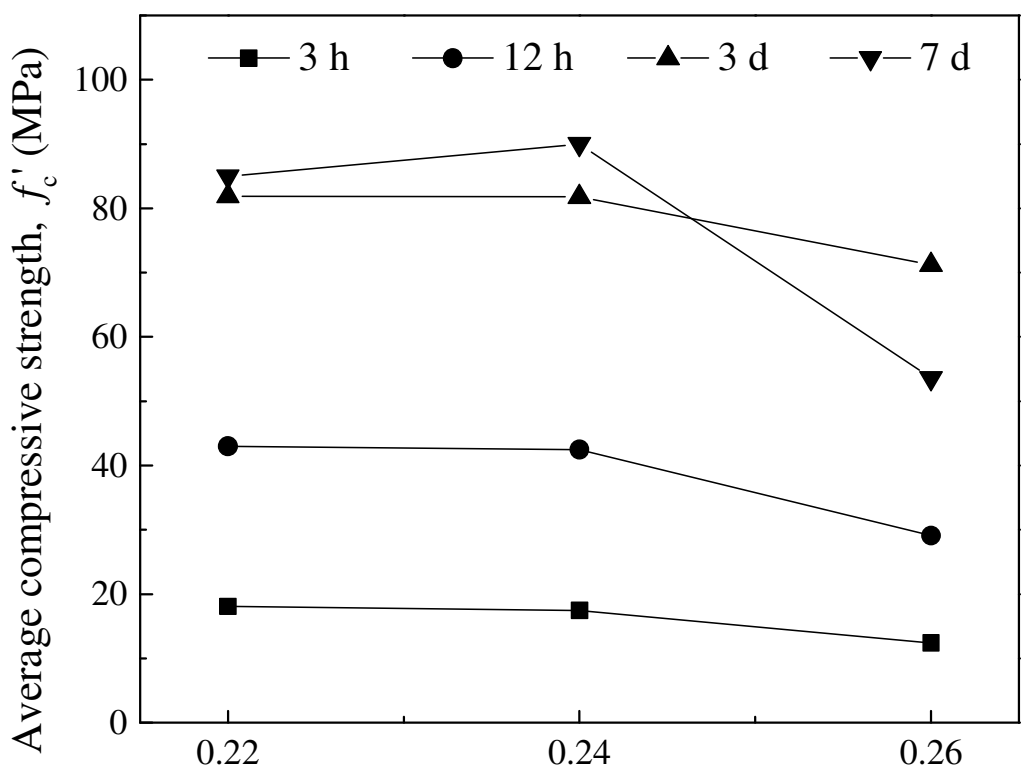

Water-binder ratio, $w / b$

(a)

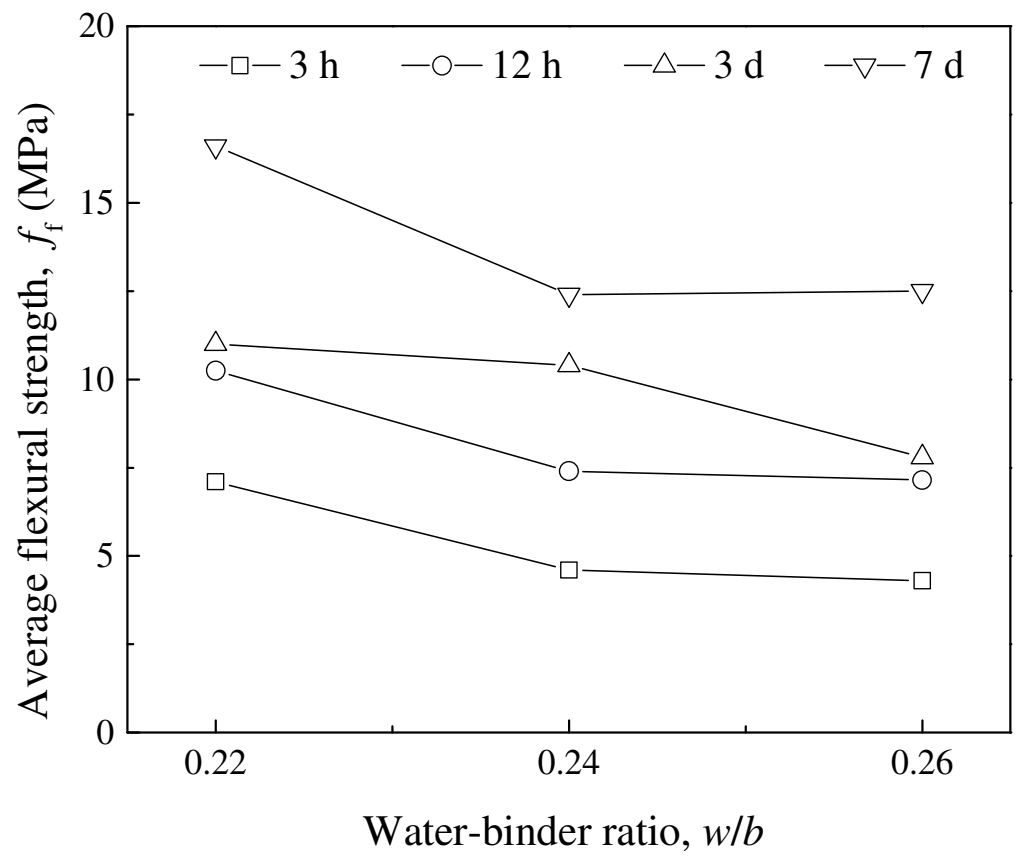

551 Fig. 7 Effect of water-binder ratios on: (a) average compressive strength, $f_{c}^{\prime}$ and (b) average flexural strength, $f_{\mathrm{f}}$ 


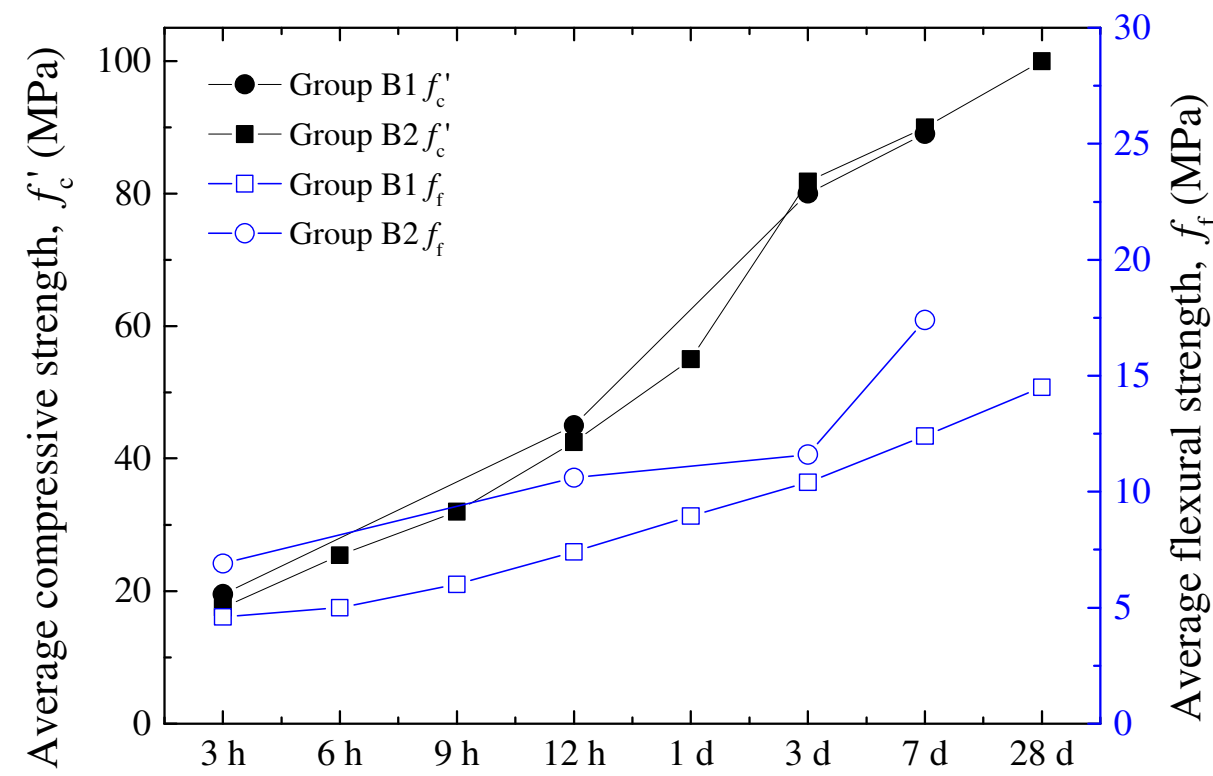

554

Curing time, $t$

555 Fig. 8 Average compressive strength, $f_{\mathrm{c}}^{\prime}$ and average flexural strength, $f_{\mathrm{f}}$ with varying curing time, 


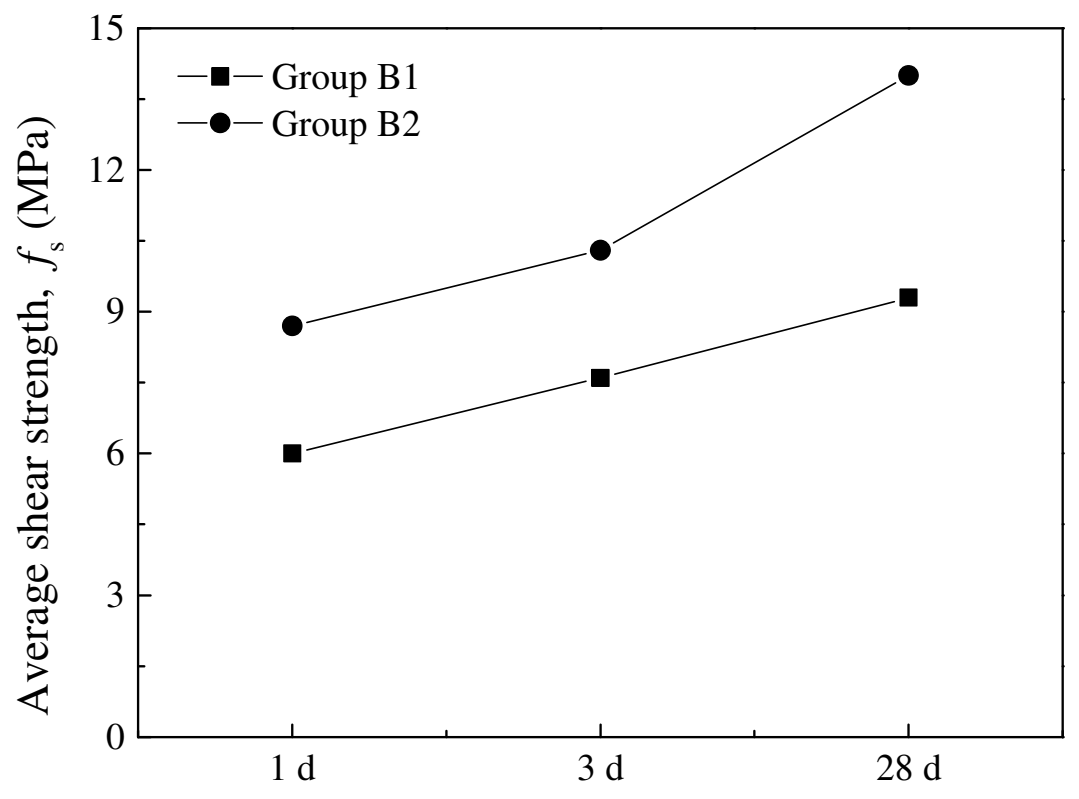

559

Curing time, $t$

(a)

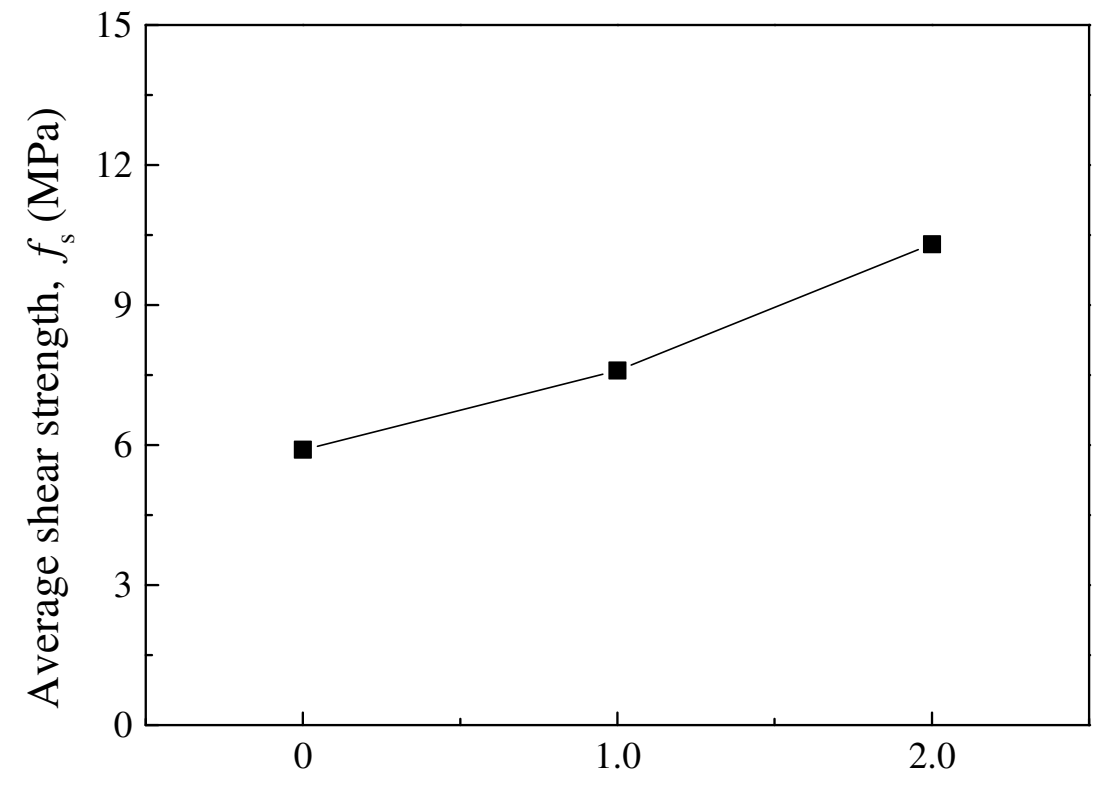

561

Volume fraction of MSF, $\rho_{\mathrm{f}}(\%)$

(b)

563 Fig. 9 Average shear strength, $f_{\mathrm{s}}$ with varying (a) curing time, $t$ and (b) MSF volume fractions, $\rho_{\mathrm{f}}$ 


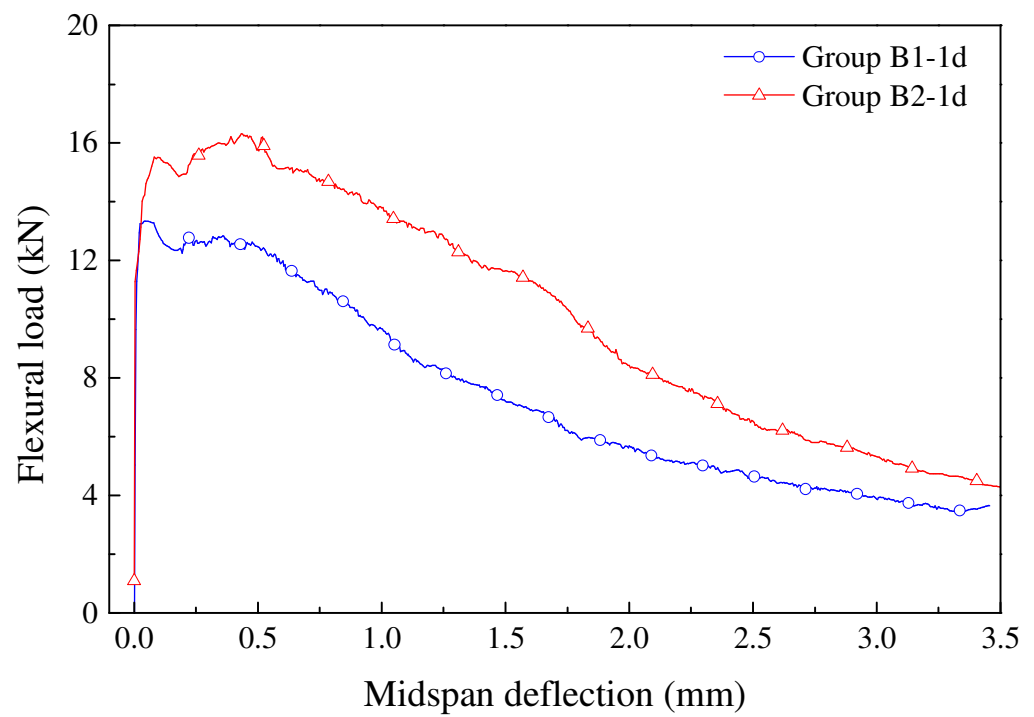

(a)

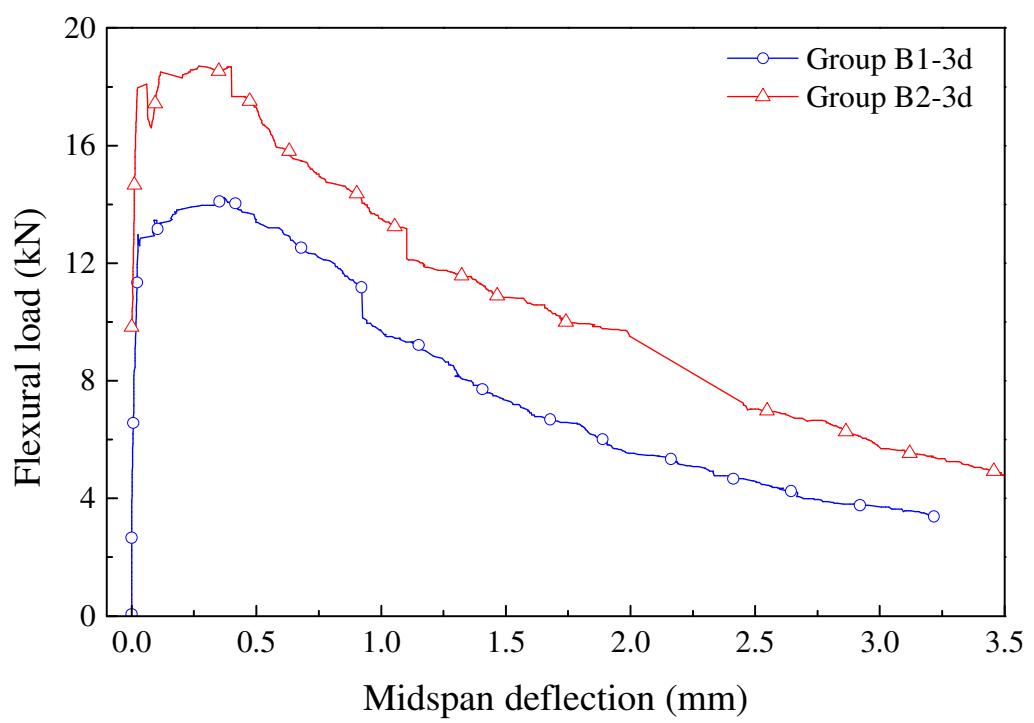

(b)

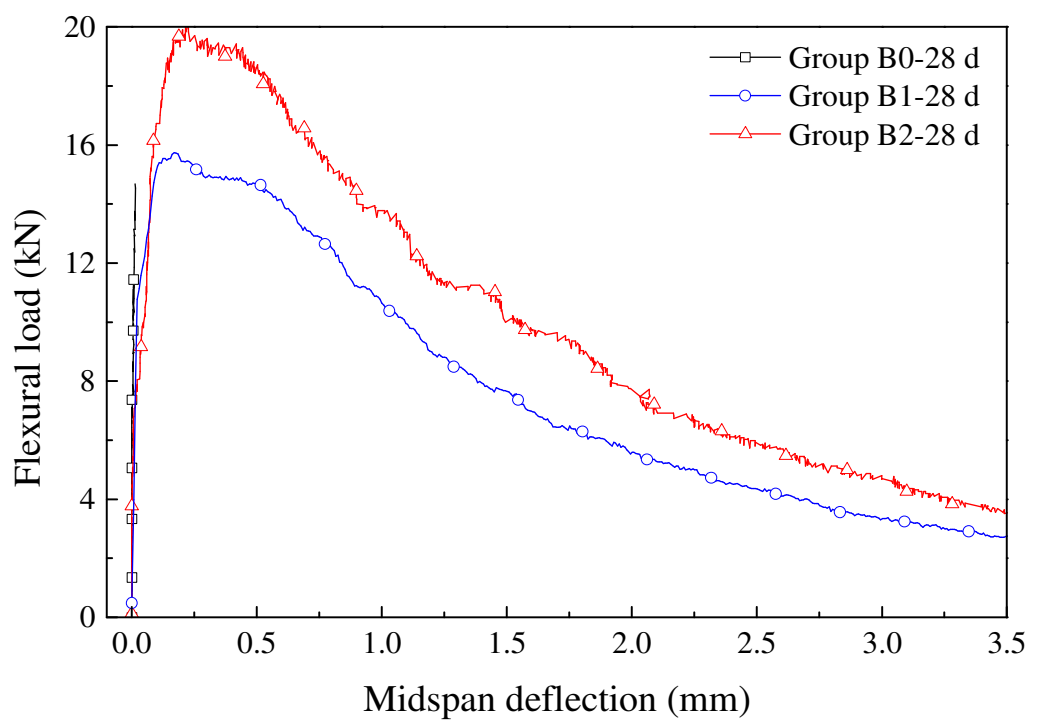

570 Fig. 10 Flexural load-midspan deflection curves of specimens with the addition of MSF by volume at curing time: (a) $1 \mathrm{~d}$, (b) $3 \mathrm{~d}$ and (c) $28 \mathrm{~d}$ 


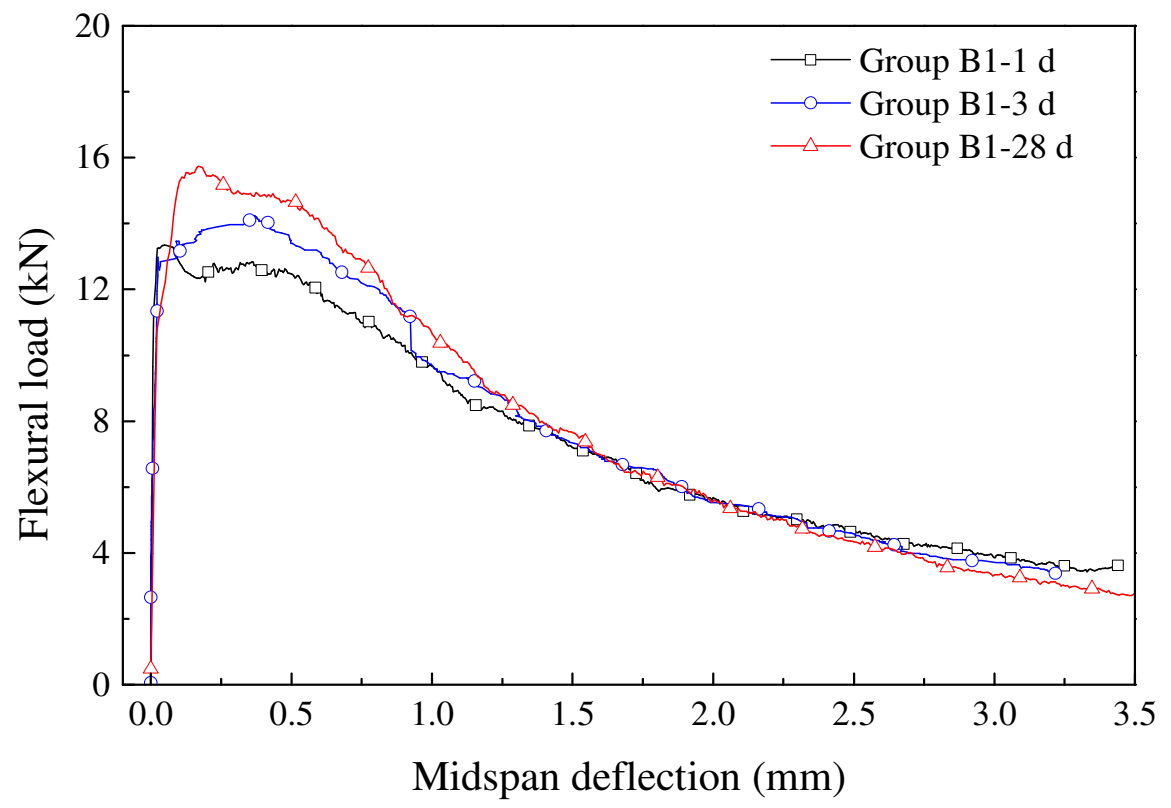

(a)

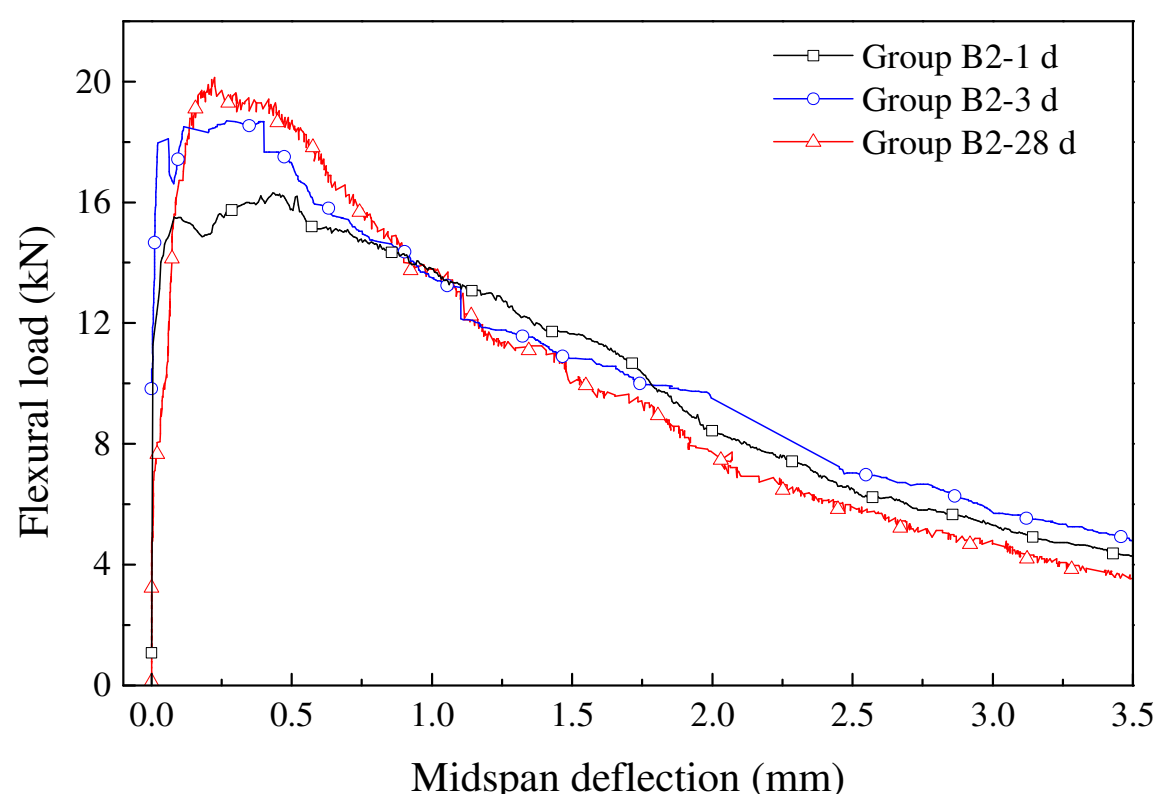

(b)

577 Fig. 11 Flexural load-midspan deflection curves of specimens with varying curing time added MSF: 


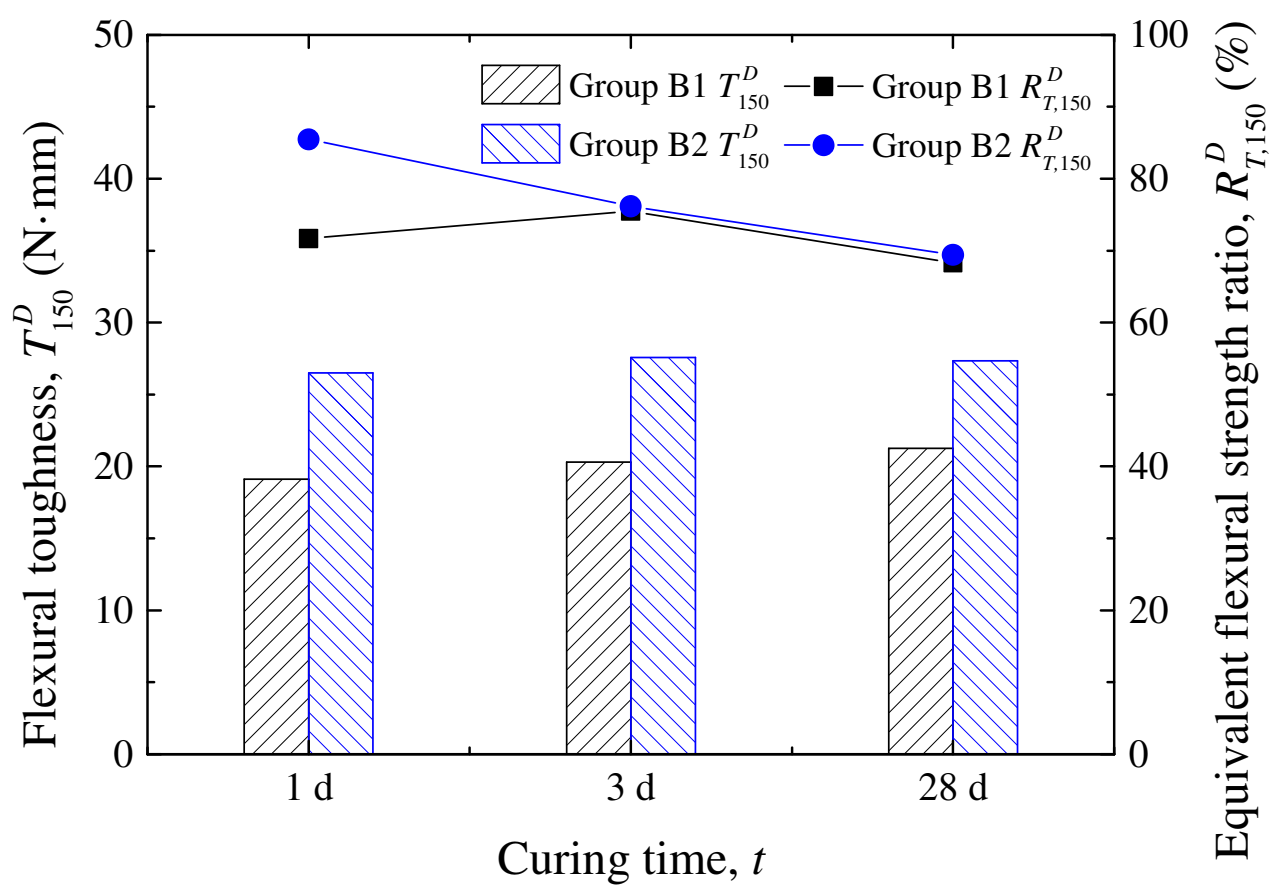




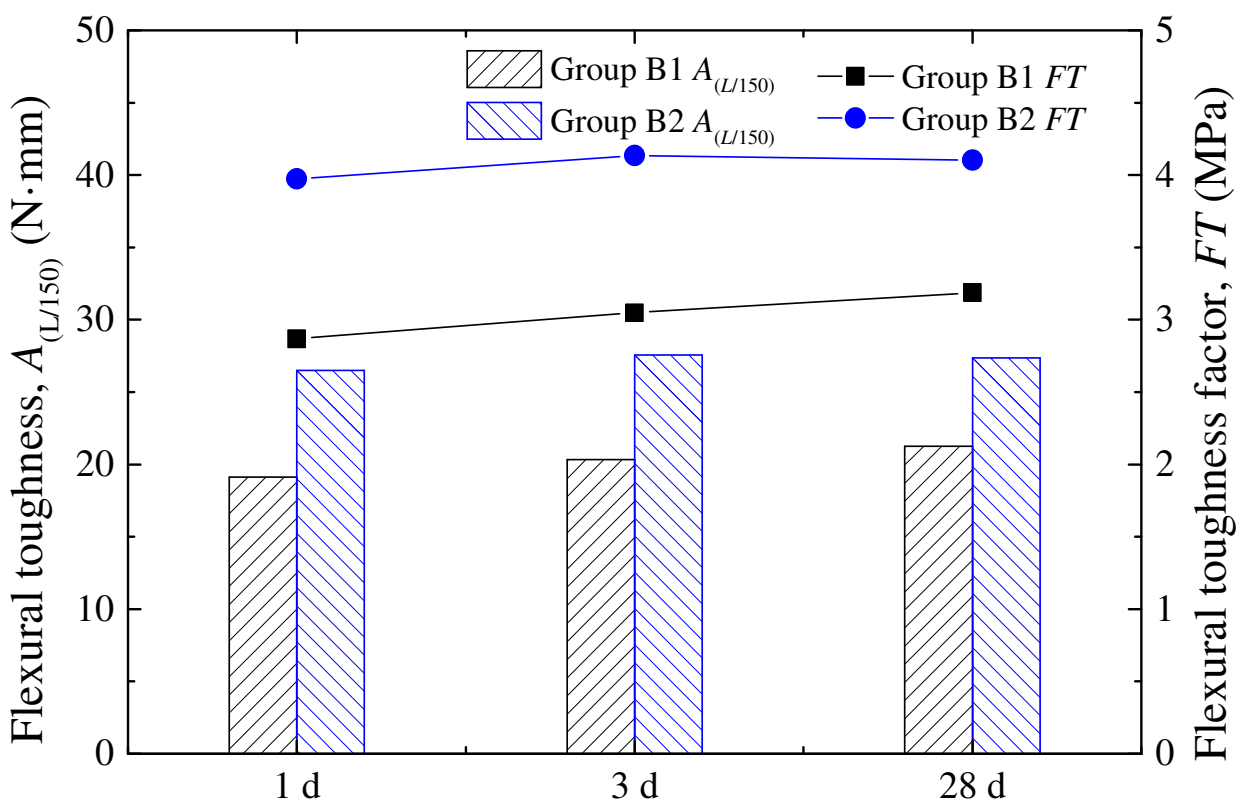

Curing time, $t$

Fig. 13 Flexural toughness index according to JSCE SF-4 [29]

587 


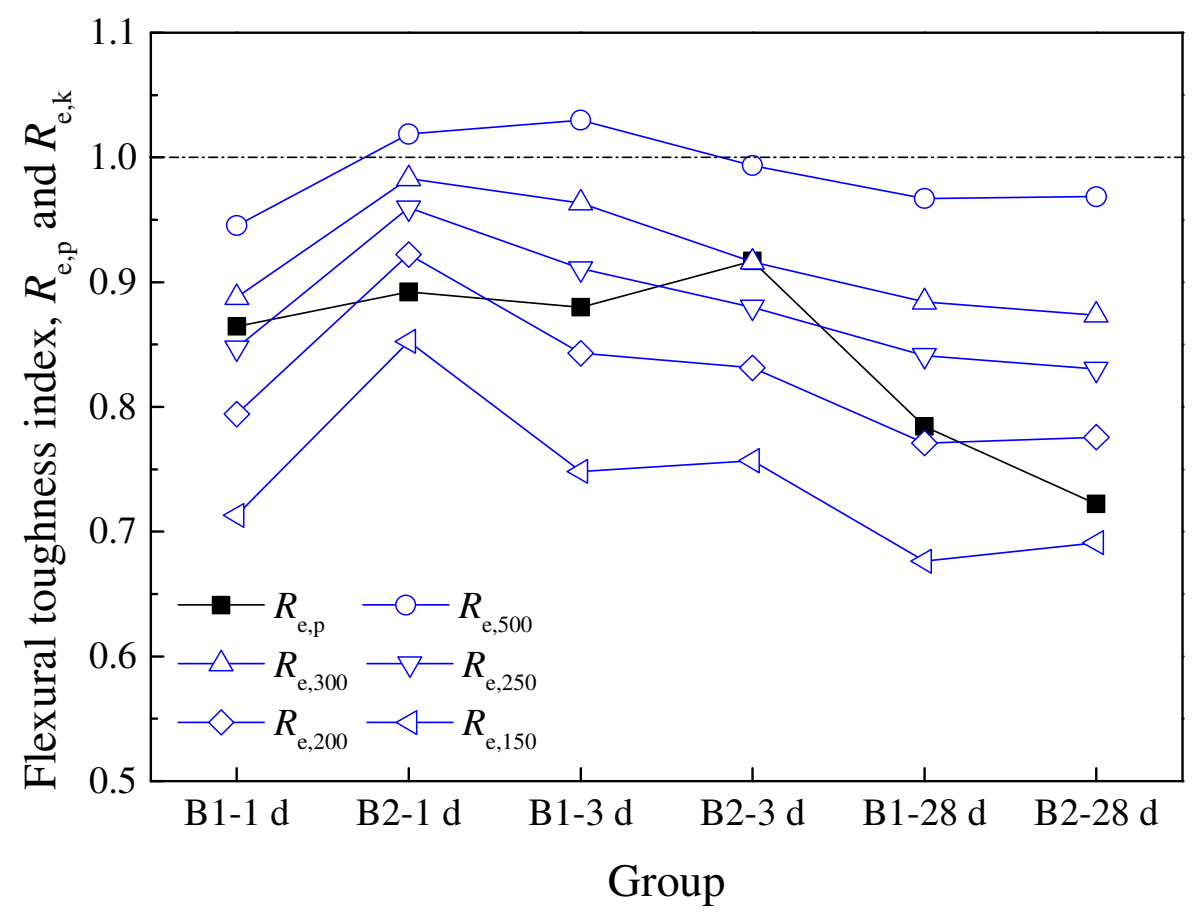

Fig. 14 Flexural toughness index according to JG/T 472-2015 [26]

591 